\title{
HABILIDADE DE ATENÇÃO AUDITIVA EM CRIANÇAS DE SETE ANOS COM FISSURA LABIOPALATINA: ESTUDO \\ COMPARATIVO
}

Isabel Cristina Cavalcanti Lemos

Dissertação apresentada à Faculdade de Odontologia de Bauru, da Universidade de São Paulo, como parte dos requisitos para obtenção do título de Mestre em Fonoaudiologia. 


\section{HABILIDADE DE ATENÇÃO AUDITIVA EM CRIANÇAS DE SETE ANOS COM FISSURA LABIOPALATINA: ESTUDO \\ COMPARATIVO}

Isabel Cristina Cavalcanti Lemos

Dissertação apresentada à Faculdade de Odontologia de Bauru, da Universidade de São Paulo, como parte dos requisitos para obtenção do título de Mestre em Fonoaudiologia.

Orientadora: Profa. Dra. Mariza Ribeiro Feniman 
Habilidade de atenção auditiva em crianças de sete anos com fissura labiopalatina: estudo comparativo / Isabel Cristina Cavalcanti Lemos. - Bauru, 2007. 98 p.: il.; $31 \mathrm{~cm}$. Bauru. USP

Dissertação. (Mestrado) - Faculdade de Odontologia de Orientador: Profa ${ }^{\text {. }}{ }^{\mathrm{a}}$. Mariza Ribeiro Feniman

Autorizo, exclusivamente para fins acadêmicos e científicos, a reprodução total ou parcial desta dissertação/tese, por processos fotocopiadores e outros meios eletrônicos.

Assinatura: 


\section{Isabel Cristina Cavalcanti Lemos}

10 de dezembro de 1982

São José dos Campos - SP

2001-2004

2005-2007
Nascimento

Curso de graduação em

Fonoaudiologia - Faculdade de

Odontologia de Bauru - Universidade de São Paulo - Bauru - SP.

Curso de Pós-Graduação em

Fonoaudiologia, em nível de Mestrado, na Faculdade de Odontologia de Bauru - Universidade de São Paulo. 
Dedico este trabalho à minha família, que me ofereceu alicerces para chegar até aqui. 
A sabedoria não pode ser comunicada por outro, pois ela é a fonte incomunicável que deve ser descoberta por você mesmo, da qual você colhe néctar como de uma flor invisível ... a sabedoria não é uma questão de aprender fatos com a mente; ela somente pode ser obtida pela perfeição do viver

N. Sri Ram 


\section{AgRAdECIMENTOS}

À Profa. Dra. MARIZA RIBEIRo Feniman,

pela disponibilidade e disposição para esclarecimentos e orientações, sempre tranqüila e compreensiva.

Às colegas de trabalho Camila Zotelli Monteiro, Renata ArRuda Camargo e ARIANE CRIStina SampaIo Rissato, pelo auxílio neste trabalho e pelo crescimento profissional e pessoal.

Ao estatístico MARCEL TAGA, responsável pela análise estatística, pela disponibilidade, atenção e auxílio.

À Dra. Sandra de Oliveira Saes e à Dra. Fátima Cristina Alves BrancoBARREIRO, pelas contribuições e participação na banca do exame de qualificação.

À amiga Janaína Regina Bosso,

pelas leituras e sugestões valiosas.

À MARLY R. M. FeRnANDES,

pela revisão da língua portuguesa e formatação.

À Profa. Fernanda Ribeiro Pinto de Carvalho, responsável pela versão do resumo em inglês.

Aos professores Dra Adriane Mortari Moret, Dr. Alberto Consolaro, Dra Alcione Ghedini Brasolotto, Ms. Ana Cristina Minervino Musa, Dra. Dagma Venturini Marques Abramides, Dr $^{\mathrm{a}}$ Dionísia Aparecida Cusin 
Lamônica, Dra Giédre Berretin Felix, Dr. José Roberto Pereira Lauris, Dr. JoÃo Candido Fernandes, Dra ${ }^{\mathrm{a}}$. Kátia de Freitas Alvarenga, Dra ${ }^{\mathrm{a}}$. Kátia Flores Genaro, Dra ${ }^{a}$. Lídia Cristina Teles Magalhães, Dra l. luciana Paula Maximino De Vitto, Dra. Magali de Lourdes Caldana, Dra. Maria Aparecida Miranda de Paula Machado, Dra. Maria Cecília Bevilacqua, Dra. Maria Inês Pegoraro-Krook, Dr. Orozimbo Alves Costa Filho, Dra. Patrícia de Abreu Pinheiro Crenitte, Dra Simone Aparecida lopes-Herrera, Dra Simone Rocha de Vasconcelos Hage e Dra. Wanderléia Q. Blasca, pelos conhecimentos que adquiri durante o curso de Mestrado.

Em especial, à Dra ANDRÉA Cintra LoPes e Dra Deborah ViVIANE FERRAR,I pelos conselhos, carinho e amizade.

A todos os funcionários do Hospital de Reabilitação de Anomalias Craniofaciais, em especial, GUILHERME, CIDA, MÁRCIA do CPD, funcionários e profissionais do Setor de Genética, pelo convívio, auxílio e concessão do espaço físico e equipamentos utilizados.

Aos funcionários da Unidade de Ensino e Pesquisa do Hospital de Reabilitação de Anomalias Craniofaciais e do Serviço de Biblioteca e Documentação da Faculdade de Odontologia de Bauru, pela atenção, disponibilidade e assessoria bibliográfica.

Às colegas de turma do curso de Mestrado ANA Dolores, DANIELA, DAPHINE, Josiane, luciana Biral, luciana Silva, Mariana, Maria Cecília, Simone e VANESSA, pela amizade, companheirismo e auxílio. 
A Almir Cavalcanti lemos Filho, meu pai, Berenice Jussara Kerber Cavalcanti lemos, minha mãe, André Vitor Kerber CaValcanti lemos, meu irmão, LUIz FELIPE COAN BRocCA e todas as amigas, por todo o apoio, carinho e incentivo.

Em especial à amiga FLÁVIA SILVEIRA LEMOS, pelo companheirismo e amizade, mesmo à distância.

Aos voluntários que participaram deste estudo.

A todos que direta ou indiretamente contribuíram para a realização deste trabalho.

Meus sinceros agradecimentos!!!! 


\section{SUMÁRIO}

LISTA DE FIGURAS

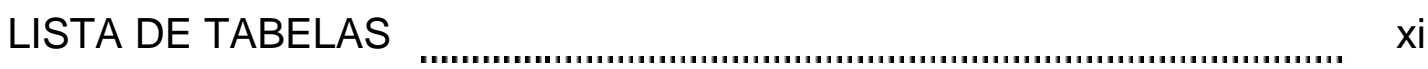

LISTA DE ABREVIATURAS _................................................................... xii

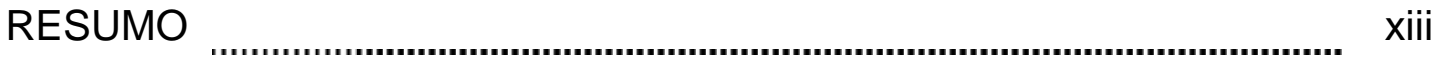

1 INTRODUÇÃO

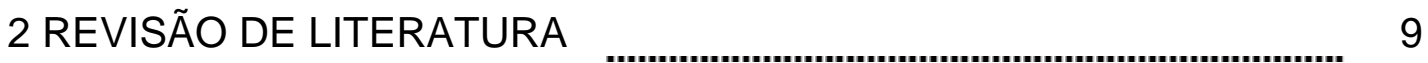

2.1 Fissura e Audição

2.2 Privação Sensorial .................................................................... 10

2.3 Fissura Labiopalatina e Função Auditiva Central $\ldots$

2.4 Atenção Auditiva .......................................................................... 17

2.5 Teste Dicótico de Dígitos ……................................................. 24

2.6 Atenção e Privação Sensorial ....................................................... 31

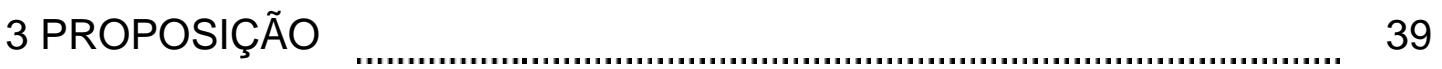

4 MATERIAIS E MÉTODO ……......................................................... 43

4.1 Casuística

4.1.1 Critérios de inclusão na amostra para o G1 _................................. 43

4.1.2 Critérios para inclusão na amostra para o G2 ………............. 43

4.1.3 Procedimentos da Seleção

4.2 Método

4.3 Análise dos Resultados

4.3.1 Análise estatística

5 RESULTADOS ………………………………………………. 55

5.1 THAAS

5.2 Dicótico de Dígitos

5.3 THAAS X Dicótico de Dígitos ……......................................... 59

4 DISCUSSÃO

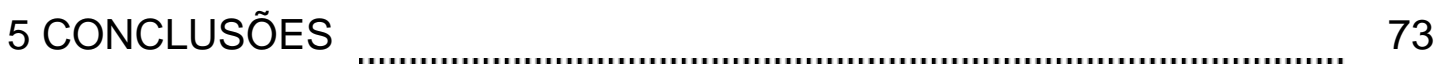

ANEXOS 76

REFERÊNCIAS BIBLIOGRÁFICAS _..................................................... 89

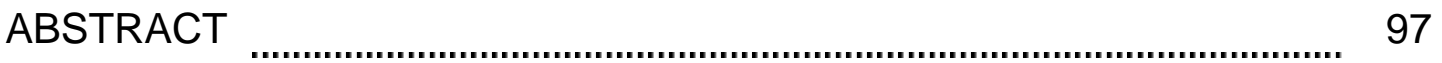




\section{LISTA DE FIGURAS}

FIGURA 1 - Número de indivíduos em cada grupo distribuídos por gênero _... 47

FIGURA 2 - Número de indivíduos em cada grupo distribuídos por gênero _... 55

FIGURA 3 - Porcentagem de acertos no teste Dicótico de Dígitos para a orelha direita (OD) e para a orelha esquerda (OE) nos dois grupos 


\section{LISTA DE TABELAS}

TABELA 1 - Valores de média, desvio-padrão, mínimo, mediana e máximo para as respostas do teste THAAS

TABELA 2 - Análise de variância com 2 fatores das variáveis do teste THAAS

TABELA 3 - Valores de média, desvio-padrão, mínimo, mediana e máximo para a orelha direita e esquerda no teste Dicótico de Dígitos

TABELA 4 - Análise de variância com medidas repetidas para o teste Dicó tico de Dígitos

TABELA 5 Comparações post hoc da análise de variância com medidas repetidas

TABELA 6 Modelos de regressão finais para o total de erros e decrescimo da vigilância do teste THAAS 59 


\section{LISTA DE ABREVIATURAS}

\begin{tabular}{|c|c|}
\hline ACPT & auditory continuous performance teste \\
\hline DCV & dichotic consonant vowel \\
\hline DRT & dichotic rhyme test \\
\hline FLP & fissura labiopalatina \\
\hline G1 & grupo controle \\
\hline G2 & grupo experimental \\
\hline HRAC & Hospital de Reabilitação de Anomalias Craniofaciais \\
\hline MLD & masking level diference \\
\hline MRI & magnectic resonace image (ressonância magnética por imagem) \\
\hline OD & orelha direita \\
\hline OE & orelha esquerda \\
\hline OM & orelha média \\
\hline OME & otite média com efusão \\
\hline PET & $\begin{array}{l}\text { Positron Emition Tomography (Tomografia de Emissão de } \\
\text { Pósitron) }\end{array}$ \\
\hline PSI & Pediatric Speech Intelligibility \\
\hline SAA & Sustained Auditory Attention (atenção auditiva sustentada) \\
\hline TDAH & Transtorno do Déficit de Atenção / Hiperatividade \\
\hline THAAS & Teste da Habilidade de Atenção Auditiva Sustentada \\
\hline PA & Transtorno do Processamento Auditivo \\
\hline
\end{tabular}




\section{Resumo}

A fissura labiopalatina é um indicador de risco para alterações de orelha média e estas podem prejudicar o desenvolvimento de habilidades auditivas como, por exemplo, a atenção, que é essencial para o aprendizado de novas habilidades, inclusive da comunicação oral e escrita. O estudo do processo atencional na população com fissura labiopalatina é algo recente e pouco explorado na literatura específica consultada, assim, este trabalho poderá contribuir com novos subsídios na área, uma vez que teve como objetivos: a) verificar o desempenho de crianças com essa anomalia craniofacial em dois testes, o THAAS e o teste dicótico de dígitos (etapa de escuta direcionada, que avaliaram processos de atenção auditiva); b) comparar o resultado com um grupo sem fissura labiopalatina e; c) verificar a associação entre os dois testes aplicados. Fizeram parte do estudo 55 crianças, de ambos os gêneros, na faixa etária de 7 anos a 7 anos e 11 meses, que foram distribuídas em dois grupos: a) grupo controle, formado por crianças sem fissura labiopalatina; b) grupo experimental, formado por crianças com fissura labiopalatina. Para ambos os grupos, o processo de avaliação constituiu-se em: aplicação de um questionário; bateria de testes auditivos convencionais; aplicação do teste da habilidade de atenção auditiva (THAAS) (FENIMAN, 2004) e do teste dicótico de dígitos etapa de escuta direcionada (SANTOS; PEREIRA, 1997). Foi possível observar que o desempenho do grupo com fissura labiopalatina foi inferior ao do grupo controle em todos os tipos de resposta do THAAS e diferença estatisticamente significativa ocorreu para o decréscimo da vigilância 
$(p=0,014)$. No teste dicótico de dígitos - etapa de escuta direcionada, o grupo com fissura labiopalatina apresentou porcentagens de acerto inferiores ao grupo controle, tanto para a orelha direita quanto para a orelha esquerda. A análise estatística mostrou interação estatisticamente significante entre grupo e gênero $(p=0,026)$. Ao comparar o THAAS com o teste dicótico de dígitos, foi possível observar que existe associação entre os testes, mas, essa associação mostrou-se muito baixa $\left(R^{2}=0,27\right)$. As crianças com fissura labiopalatina apresentaram desempenho no THAAS inferior àquelas sem esta anomalia craniofacial, apenas para o decréscimo da vigilância. No teste dicótico de dígitos - etapa de escuta direcionada, somente as crianças do gênero feminino com fissura labiopalatina obtiveram índices de acerto inferiores às do grupo controle. Uma baixa associação foi verificada entre o THAAS e o teste dicótico de dígitos - etapa de escuta direcionada, permitindo supor que habilidades diferentes são responsáveis pelo desempenho nos dois testes.

Palavras-chave: Fissura Palatina. Atenção. Privação Sensorial. Otite Média Secretora 
$\mathfrak{l} \mathfrak{J}_{\mathfrak{n t r a t a} \mathfrak{u} \mathfrak{x} \tilde{\mathfrak{a}} \mathfrak{a}}$ 



\section{INTRODUÇÃO}

As fissuras labiopalatinas congênitas (FLP) desenvolvem-se de maneira disforme na face, durante o período embrionário e o início do fetal, sendo representadas, clinicamente, pela ausência do fechamento do lábio, palato ou ambos. Sabe-se que, nessa população, a presença da otite média com efusão (OME), atribuída à disfunção da tuba auditiva, é quase universal. Isso ocorre pela falta de fusão da musculatura do palato, o que reforça a teoria da hipoventilação da orelha média (OM) como uma das teorias de etiopatogenia da OME. Os músculos tensor e elevador do palato, perdendo o apoio do correspondente contralateral, deixam de abrir eficazmente a tuba auditiva, pela deformação do esqueleto cartilaginoso (ALMEIDA¹, 1999).

A OME é uma forma especial de otite média, de instalação silenciosa, que se caracteriza pelo acúmulo, na orelha média, de líquido seroso ou de um líquido mucoso tipo "cola" (termo originado do inglês glue ear). Essa doença constitui, atualmente, uma das causas mais comuns de hipoacusia, frequentemente bilateral, em crianças até 10 anos de idade (HUNGRIA ${ }^{33}$, 2000).

Apesar de a acuidade auditiva estar presente intra-útero, tal fato não é suficiente para que a criança compreenda informações auditivas e as utilize como instrumento de comunicação. Para que isso aconteça, é necessário que ela adquira habilidades que possibilitem a análise e interpretação dos sons já detectados pelo sistema auditivo periférico (GONÇALES $\left.{ }^{22}, 2002\right)$. 
Crianças com freqüente hipoacusia, por causa de OME, podem apresentar prejuízo no desenvolvimento de habilidades auditivas, uma vez que um sistema auditivo com alteração periférica pode ser incapaz de decodificar corretamente a mensagem, levando o ouvinte a receber mensagens distorcidas e incompletas. O desenvolvimento das habilidades auditivas envolvidas no processamento auditivo depende de uma capacidade inata e biológica do indivíduo, bem como de sua experiência com o meio. Alterações nessas habilidades podem levar a prejuízos no desempenho acadêmico, atraso de linguagem, dificuldade para entender apropriadamente o que the é dito e dificuldade de aprendizagem.

Perdas auditivas condutivas nos primeiros anos de vida podem levar a transtornos do processamento auditivo, de atenção e, conseqüentemente, dificuldades de aprendizado da comunicação.

A atenção está presente no dia-a-dia, possibilitando selecionar quais estímulos endógenos e exógenos são importantes para a realização de tarefas. A atenção auditiva, especificamente, é a habilidade de o indivíduo de se preparar, focar um estímulo sonoro, e ainda estar pronto para receber um estímulo diferente em qualquer tempo. É um aspecto imprescindível para a aquisição de aspectos acústicos e fonéticos dos padrões lingüísticos, essenciais no processo de aprendizagem da leitura e escrita. Existem diferentes tipos de atenção auditiva, um dele é a atenção auditiva sustentada, definida como a habilidade de manter o foco atencional por um período de tempo (GOMES et al. $\left.{ }^{21}, 2000\right)$. 
Uma das maiores causas de fracasso escolar entre as crianças é a falta de atenção. O problema de atenção pode ser a manifestação de certo número de doenças, incluindo o Transtorno de Déficit de Atenção e Hiperatividade (TDAH) e o Transtorno do Processamento Auditivo, entre outros. Mas, ainda não há um consenso em determinar se a dificuldade na atenção auditiva é um componente associado ao Transtorno do Processamento Auditivo (TPA) ou reflete apenas um déficit isolado no processo de atenção.

Portanto, verificar a habilidade de atenção auditiva sustentada em crianças com fissura labiopalatina é essencial, uma vez que essas crianças vivenciam longos períodos de privação sensorial, os quais podem gerar alterações nas habilidades auditivas, inclusive de atenção. 



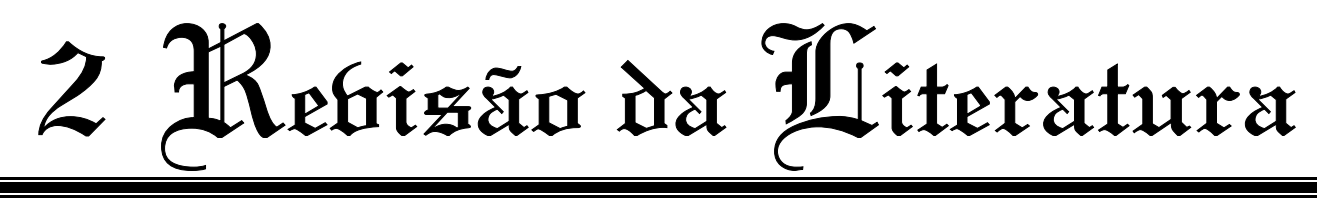





\section{REVISÃO DA LITERATURA}

\subsection{Fissura e Audição}

A alteração de OM na população com FLP já é um consenso na literatura. HANDZIC-CUK et al., 2001, analisaram a timpanometria de 239 indivíduos com fissura labiopalatina e observaram que: $46,5 \%$ dos indivíduos com fissura transforame bilateral tinham timpanograma tipo $B$, o grupo com fissura transforame unilateral teve freqüência de 50,6\% de timpanogramas tipo B e a freqüência desse tipo de timpanograma na fissura de palato isolada foi de $58,3 \%$. Os timpanogramas tipo A foram mais freqüentes nas crianças mais velhas (média de 11 anos), aumentando significativamente com a idade; o tipo $B$ foi mais freqüente nas crianças com média de 5 anos, diminuindo significativamente com o aumento da idade; e, o tipo $C$, nas crianças com média de 6 anos, sem significância com a idade.

TUNÇBILEK; OZGUR; BELGIN ${ }^{77}$, 2003, avaliaram otológica e audiologicamente 100 orelhas de crianças com fissura labiopalatina. Foi observado que apenas 40 orelhas tinham a pressão do pico dentro dos padrões de normalidade e que $24 \%$ das crianças tinham alteração na pressão do pico em apenas uma orelha, enquanto $50 \%$ tinham em ambas as orelhas. Os autores ressaltaram que a condição auditiva final de pacientes com fissura labiopalatina é o resultado da combinação do tipo de técnica na correção cirúrgica do palato, de fatores relacionados ao desenvolvimento da criança e do tratamento precoce de doenças da orelha média.

CHU; MCPHERSON ${ }^{12}, 2005$, analisaram a condição otológica e 


\section{REVISÃo dA LITERATURA}

audiológica de crianças e adultos jovens chineses, com fissura labiopalatina. Os autores observaram que $23,7 \%$ tinham timpanogramas alterados e que essa ocorrência é menor do que a observada em outros países ocidentais, mas, entenderam que a discrepância pode dever-se à diferença racial.

Em um estudo que procurou descrever os centros audiológicos que cuidavam de crianças com fissura labiopalatina, MOSS; FONSECA ${ }^{53}, 2006$, relataram que a informação auditiva dessas crianças não vem sendo devidamente verificada e que os pais não estão bem informados a respeito das possíveis alterações audiológicas que seus filhos com fissura labiopalatina podem apresentar. Os autores sugeriram um modelo clínico adequado para avaliação, tratamento e acompanhamento audiológico dessas crianças.

HOCEVAR-BOLTEZAR; JARC; KOZELJ ${ }^{30}, 2006$, estudaram a prevalência de alterações de orelha, nariz e voz em 80 crianças com fissura de palato e $73 \mathrm{com}$ fissura transforame. Alterações nas vias auditivas foram encontradas em $53,8 \%$ e $58,9 \%$, respectivamente.

GOUDY et al. ${ }^{24}, 2006$, estudaram a ocorrência de perda auditiva condutiva e patologias da orelha em 101 indivíduos com fissura de palato, com idades entre 8 e 25 anos. Foi encontrada perda auditiva condutiva em $25 \%$ dos indivíduos estudados, entre os quais $75 \%$ tinham uma perda leve, $21 \%$ moderada e $4 \%$ severa.

\subsection{Privação Sensorial}

$\mathrm{Na}$ literatura, especialmente quando se trata de crianças, é muito 
discutida a questão das possíveis seqüelas de linguagem, de comportamento, acadêmicas, cognitivas e/ou no processamento auditivo, provocadas, a longo prazo, pela presença de alterações de orelha média, associadas à diminuição da acuidade auditiva.

A fim de determinar alterações intelectuais e lingüísticas como seqüelas de doenças de orelha média, TEELE et al. ${ }^{75}, 1990$, acompanharam 194 crianças, do nascimento até os sete anos. As crianças foram avaliadas por meio de otoscopia e timpanometria, para a determinação da presença ou não de otite desde os três meses de idade. Aos sete anos, elas foram avaliadas quanto à cognição, desempenho acadêmico, fala e linguagem. Os resultados mostraram que as crianças que tiveram otites recorrentes, durante o primeiro ano de vida, obtiveram pior desempenho em relação à cognição, desempenho acadêmico, fala e linguagem do que aquelas sem histórico de otites recorrentes.

GRAVEL; WALLACE; RUBEN ${ }^{26}, 1996$, avaliaram crianças durante o primeiro ano de vida, para determinar a presença ou não de otite e perda auditiva. Assim, foram constituídos dois grupos: um com histórico de otite e perda auditiva no primeiro ano de vida e outro sem esse histórico. Posteriormente, essas crianças foram avaliadas aos quatro, aos seis e aos nove anos de idade. Aos quatro anos foram avaliadas quanto à linguagem, comportamento, limiares auditivos e capacidade de ouvir a fala no ruído; aos seis anos foram avaliados o desempenho acadêmico e cognitivo, além de os professores responderem a um questionário sobre o desempenho na sala de aula; aos nove anos foram avaliadas a linguagem, o masking level diference 


\section{REVISÃo dA LITERATURA}

(MLD), a capacidade de reconhecimento auditivo com fala competitiva e a memória. Os resultados obtidos sugeriram que perdas auditivas condutivas no primeiro ano de vida podem, futuramente, influenciar habilidades auditivas importantes para o desempenho na sala de aula e para o comportamento.

Procurando encontrar associação entre OME nos dois primeiros anos de vida, e alterações cognitivas e de linguagem aos dois anos de idade, ROBERTS et al. ${ }^{63}, 1998$, estudaram 86 crianças e concluíram que a OME e a deficiência auditiva causada por ela estão mais relacionadas com as qualidades do meio em que a criança vive e de seus cuidadores do que com seu desenvolvimento de linguagem e cognitivo.

BRODY et al. ${ }^{9}, 1999$, avaliaram as condições auditivas de 115 crianças que freqüentaram um hospital pediátrico. Os pais dessas crianças foram instruídos a preencher um questionário, desenvolvido pelos próprios autores, relacionado à audição da criança. Os autores concluíram que a percepção dos pais sobre a audição de seus filhos com OME não era assertiva e recomendaram que a audição das crianças com OME fosse devidamente acompanhada.

No estudo de STEWART et al. ${ }^{73}, 1999$, os pais de 113 crianças, entre um e nove anos de idade, responderam a um questionário sobre a audição de seus filhos antes e seis meses depois de cirurgia para colocação de tubo de ventilação. Os autores relataram que a percepção dos pais sobre a perda auditiva de seus filhos tem uma correlação muito pobre com os limiares encontrados em audiometria e concluíram que utilizar a percepção dos pais 
para realizar triagem antes de uma avaliação auditiva pode não ser uma boa prática.

SANTOS et al. ${ }^{68}, 2001$, analisaram a influência da otite média no desempenho de 25 crianças, com idade entre seis e 13 anos, e com queixas relacionadas a alterações do processamento auditivo. Foram formados dois grupos: ${ }^{\text {a) }} 10$ crianças com queixa de processamento auditivo e antecedente de otite média; e, b) 15 crianças com queixa de processamento auditivo e sem antecedente de otite média. Os testes utilizados para avaliar o processamento auditivo foram: localização sonora em cinco direções, memória para sons verbais e não-verbais em seqüência, fala com ruído branco, dicótico de dígitos - etapa de integração biaural, dicótico não-verbal, e reconhecimento de frases com mensagem competitiva contralateral e ipsilateral. A presença do histórico de otite média não piorou o desempenho em nenhum dos testes. Os autores concluíram que crianças com antecedentes de otites médias recorrentes, encaminhadas por queixas que levantam suspeitas de alterações de processamento auditivo central, comportam-se, em relação à medida das habilidades auditivas, de modo semelhante ao daquelas sem antecedentes de otite.

ROBERTS; BURCHINAL; ZEISEL ${ }^{64}, 2002$, examinaram se OME, com deficiência auditiva associada, nos primeiros quarto anos de vida, estava relacionada aos desenvolvimentos de linguagem e acadêmico de 83 crianças, aos quatro anos. Os autores não encontraram evidencias de correlação significativa entre OME ou deficiência auditiva e o desempenho acadêmico das crianças em leitura ou reconhecimento de palavras, durante os primeiros anos 


\section{REVISÃo dA LITERATURA}

escolares. As crianças que apresentavam maior ocorrência de OME e deficiência auditiva tiveram desempenho inferior em matemática e linguagem expressiva em idades anteriores, mas, recuperaram seu desenvolvimento e se igualaram ao grupo controle aos quatro anos de idade.

Para determinar se otites freqüentes podem afetar a audição biaural de crianças com seis anos de idade, HOGAN; MOORE ${ }^{31}, 2003$, estudaram 31 crianças com histórico de otites freqüentes. Em todas foi aplicado o teste MLD, um edis da audição biaural. Os resultados mostraram que as crianças que tiveram OME em aproximadamente metade de suas vidas até os 5 anos de idade, apresentavam resíduos de alteração na audição biaural aos 6 anos de idade.

SAES; GOLDBERG; MANTOVANI ${ }^{65}, 2005$, avaliaram a ocorrência e recorrência de secreção na orelha media, e os possíveis fatores associados, em 190 recém-nascidos e lactentes observados mensalmente nos dois primeiros anos de vida. Os autores relataram que $68,4 \%$ dos lactentes apresentaram um ou mais episódios de secreção na orelha média e que a presença de tabagismo passivo, refluxo gastresofágico e infecções de vias aéreas superiores estiveram relacionados à recorrência de efusão.

JUNG et al. ${ }^{37}, 2005$, realizaram uma revisão de literatura a fim de determinar as complicações e seqüelas da OME. Um dos aspectos avaliados foi a função auditiva central e os autores observaram que diversos estudos eram consistentes em mostrar que mudanças auditivas centrais parecem estar relacionadas ao histórico de OME. Concluíram que eram necessários estudos randomizados para determinar essa causalidade. 
FUCCI; FARIA; PAULA ${ }^{18}, 2005$, estudaram o processamento auditivo de 13 crianças com histórico de otites recorrentes na infância. Concluíram que $62 \%$ apresentaram alteração em pelo menos uma das habilidades auditivas estudadas. As habilidades mais comprometidas foram a de figura-fundo, integração biaural e memória seqüencial. Desta forma, sugeriram que a audição flutuante, ocasionada pelas otites recorrentes, pode apresentar efeitos negativos no processo de desenvolvimento do indivíduo, pois causam ineficiência nas estratégias de ouvir, algo que pode persistir apesar da inatividade da doença.

\subsection{Fissura Labiopalatina e Função Auditiva Central}

Alterações na função auditiva central de crianças com fissura labiopalatina é uma questão em estudo, mas alguns trabalhos começam a apontar os primeiro resultados.

MINARD; FENIMAN; SOUSA ${ }^{49}, 2001$, investigaram, por meio de um questionário aplicado aos pais, as habilidades auditivas do processamento auditivo na população com fissura labiopalatina. Fizeram parte do estudo 100 crianças entre sete e 12 anos de idade. Os autores concluíram que a ocorrência de manifestações sugestivas de alteração no processamento auditivo, nessas crianças, é significativa.

A fim de avaliar a função auditiva central de crianças com fissura labiopalatina, CRUZ; CAMPOS; FENIMAN ${ }^{13}$, 2002, aplicaram o teste SSW em 


\section{REVISÃo dA LITERATURA}

16 crianças com idade media de 8,5 anos. Foi possível observar que $87 \%$ das crianças apresentaram desempenho ruim em pelo menos um dos seis critérios do teste. Os autores sugeriram que uma bateria de testes para avaliação do processamento auditivo seja incluída na rotina clínica de crianças com fissura labiopalatina.

CASSAB; ZORZETTO ${ }^{11}, 2002$, investigaram as habilidades do processamento temporal (resolução temporal) em 55 crianças com e sem fissura labiopalatina e concluíram que as crianças do grupo com fissura labiopalatina apresentavam limiares de fusão auditiva sugestivos de déficit do processamento temporal, com limiares médios maiores quando comparados aos do grupo de crianças sem fissura labiopalatina.

BARUFI et al. ${ }^{6}, 2004$, aplicaram um questionário em pais, visando avaliar o comportamento de escuta de crianças com fissura labiopalatina. Participaram do estudo 98 crianças, separadas em dois grupos: ${ }^{a} 50$ crianças com fissura labiopalatina; e, ${ }^{\text {b) }} 48$ sem essa anomalia. Não houve diferença no julgamento dos pais de ambos os grupos. Os autores sugeriram que uma avaliação do processamento auditivo dessas crianças poderá identificar a real sensibilidade desse instrumento na identificação de alterações do processamento auditivo.

BELLONI; SANTOS ${ }^{8}, 2005$, analisaram o processamento auditivo de 11 crianças com fissura labiopalatina não-sindrômica e verificaram que seis sujeitos apresentavam alteração em pelo menos uma das habilidades auditivas estudadas e que $65 \%$ apresentavam alteração nos testes dicótico de dígitos e dicótico não-verbal. Concluíram que a avaliação do processamento auditivo 
deve fazer parte da avaliação fonoaudiológica de crianças portadoras de fissura labiopalatina, o que pode fornecer subsídios para a terapia.

\subsection{Atenção Auditiva}

A atenção é um processo multimodal, essencial para o aprendizado e desenvolvimento dos indivíduos (GOMES et al. $\left.{ }^{21}, 2000\right)$.

MIRSKY et al. ${ }^{51}, 1999$, desenvolveram um modelo neuropsicológico da atenção, cujo princípio geral é que as funções atencionais são diferentes e articuladas. Os autores descreveram as funções auditivas como as capacidades de: ${ }^{a)}$ Focar: concentrar a atenção numa tarefa específica e estar apto a triar estímulos periféricos distratores; ${ }^{\text {b) }}$ Sustentar: permanecer vigilante a uma tarefa por um intervalo de tempo; ${ }^{c)}$ Mudar o foco atencional de um aspecto de um estímulo para outro, de maneira flexível e eficiente; ${ }^{\text {d) }}$ Codificar: manter a informação na mente enquanto realiza algumas ações ou operações cognitivas com essa informação.

KUPIETZ; RICHARDSON ${ }^{42}$, 1977, estudaram o desempenho de 16 crianças, entre sete e 12 anos, em dois testes de leitura, um de vigilância auditiva e um de vigilância visual, e compararam com os resultados de observações do comportamento em sala de aula e com um questionário respondido pelos professores sobre agressividade, atenção e hiperatividade. Houve correlação estatística entre agressividade e hiperatividade (partes do questionário) e o teste de vigilância visual; e houve uma tendência de erros de 


\section{REVISÃo dA LITERATURA}

vigilância variarem inversamente aos escores de leitura. Os autores concluíram que o desempenho de vigilância das crianças é diretamente relacionado com sua atenção em sala de aula.

LUNDY-EKMAN ${ }^{45}, 2000$, descreveu os estágios de desenvolvimento do sistema nervoso in útero e seus distúrbios, além de relatar as modificações do sistema nervoso durante a infância.

THOMPSON $^{76}, 2005$, descreveu o desenvolvimento, plasticidade e envelhecimento do cérebro, com ênfase nos mecanismos de desenvolvimento cerebral, na plasticidade relacionada ao sistema visual e nas diversas alterações que o envelhecimento cerebral pode causar.

GAZZANIGA; IRVY; MANGUN ${ }^{19}, 2006$, descreveram os modelos teóricos de atenção, os sistemas neurais em atenção e percepção seletiva, a neurologia e a neuropsicologia da atenção, enfocando, especialmente, a atenção visual.

A atenção auditiva é essencial para o processamento da informação selecionada e para a aprendizagem de novas tarefas. GOMES et al. ${ }^{21}, 2000$, elencou cinco componentes da atenção auditiva:

- alerta, que refere-se ao preparo fisiológico para perceber e processar estímulos, estados de alerta variam de sono profundo à excitação extrema;

- orientação, que refere-se a mudanças fisiológicas e comportamentais associadas à deteç̧ão de um novo estímulo ou de um estímulo saliente; 
- atenção auditiva seletiva, que é o processo pelo qual o individuo foca-se em um estímulo específico, a fim de processar essa informação mais profundamente enquanto ignora outro estímulo, potencialmente um distrator;

- atenção auditiva dividida, que ocorre quando um indivíduo necessita atender a dois ou mais estímulos simultaneamente acredita-se que, na realidade, esse processo não seja simultâneo e sim ocorra por mudanças sucessivas e alternadas de um estímulo para outro, desta forma, a atenção dividida exige todos os processos da atenção seletiva, além da eficiência e rapidez com que essa mudança deve acontecer;

- atenção auditiva sustentada ou vigilância, que é a habilidade de manter $\mathrm{o}$ foco atencional por um período de tempo. $\mathrm{O}$ autor relatou que existe evidência de mudança do desenvolvimento em alguns dos componentes de atenção e que melhoras parecem ser primariamente atribuídas aos processos cognitivos mais altos, tais como motivação, estratégia de desenvolvimento, implementação, direção voluntária e regulamento da atenção.

GORDON; EBERHARDT; RUECKL ${ }^{23}$, 1993, relataram quatro experimentos, realizados em 12 indivíduos, que mostram a importância da atenção na percepção fonética. Os autores concluíram que a atenção é imprescindível para a aquisição de aspectos acústicos e fonéticos dos padrões 


\section{REVISÃo dA LITERATURA}

lingüísticos e que estes são essenciais no processo de aprendizagem da leitura.

MCGEE; CLARK; SYMONS ${ }^{47}, 2000$, apresentaram um teste de vigilância visual, o Conners'CPT. O teste foi aplicado em 100 crianças com idade entre 6 e 11 anos, nas quais também foi aplicado um teste de vigilância auditiva, O ACPT, a fim de comparar os resultados dos dois testes. Os resultados indicaram uma concordância de $67 \%$ entre eles, o que sugeriu que ambos medem algo em comum, mas, com métodos administrativos diferentes.

HUGDAHL et al. ${ }^{32}, 2000$, por meio do PET, estudaram o efeito da atenção na ativação cerebral em situação de escuta dicótica. Na tarefa utilizada, o indivíduo deveria pressionar um botão, indicando o lado que ouviu o estímulo-alvo (etapa de atenção dividida) e, na etapa de atenção dirigida, ele deveria pressionar o botão assim que ouvisse o estímulo-alvo na orelha pré-determinada. Os autores observaram reduções nas ativações do córtex auditivo primário durante a etapa de atenção dirigida, quando comparada à etapa de atenção dividida, concluindo que isso pode ser interpretado como um efeito facilitador da atenção no processamento da audição.

O trabalho de ORTUÑO et al. ${ }^{57}, 2002$, visou descrever mudanças relativas ao fluxo sanguíneo cerebral, usando PET durante uma tarefa de atenção sustentada que incluía estimulação auditiva e diferentes tarefas de contagem mental. Participaram do estudo 10 voluntários com padrão de normalidade em bateria de testes neurocognitivos que incluíam medidas de atenção e memória de trabalho. Os resultados confirmaram a participação de várias regiões cerebrais nas tarefas auditivas e de contagem; a participação do 
córtex cingulado em todas as análises mostra evidencias da participação desta área em tarefas de atenção sustentada.

Para MEDWETSKY ${ }^{48}, 2002$, o déficit de atenção auditiva é freqüentemente descrito com base na observação do comportamento - tal como apresentar problemas em prestar atenção em sala de aula - ou, pelas listas de características de déficit de atenção descritas no DSM-IV. O autor definiu atenção auditiva como um processo cognitivo que permite ao ouvinte focar-se seletivamente no estímulo de interesse, enquanto ignora um estímulo irrelevante competindo, além de definir os diferentes tipos de atenção (preparatória, ensaio, focada, seletiva, dividida, sustentada e vigilância).

LAURES $^{43}, 2003$, estudou o desempenho de indivíduos com afasia durante uma tarefa de vigilância com estímulos lingüísticos e não-linguísticos. Participaram do estudo 10 indivíduos afásicos e 10 sem alteração neurológica, com idades entre 42 e 71 anos. Foi possível observar que o grupo com afasia teve desempenho inferior na tarefa de vigilância, em relação ao grupo controle, e não houve diferença entre as tarefas com estímulos lingüísticos e nãolinguísticos. Portanto, indivíduos afásicos apresentam um comprometimento geral da atenção no processamento da informação auditiva e não uma alteração específica do processamento da informação lingüística.

SCHWID et al. ${ }^{69}, 2003$, mediram objetivamente a fadiga cognitiva como um declínio no desempenho em testes que necessitam da atenção auditiva sustentada. Participaram do estudo 20 indivíduos com esclerose múltipla e 21 controles. Os indivíduos com esclerose múltipla demonstraram 


\section{REVISÃo dA LITERATURA}

$5,8 \%$ de declínio no desempenho durante um dos testes administrados, enquanto nos indivíduos do grupo controle não foi observado declínio.

A fim de desenvolver um teste para avaliar a atenção sustentada e a vigilância de crianças, KEITH ${ }^{38}, 1994$, padronizou o ACPT (Auditory Continuous Performance Test) e comparou os resultados de crianças com déficit de atenção e hiperatividade com crianças que não tinham esse distúrbio. $O$ autor relatou que as crianças sem diagnóstico de déficit de atenção e hiperatividade tinham menor declínio na atenção durante a tarefa de vigilância, quando comparado às crianças com déficit de atenção e hiperatividade, e que a inclusão do teste ACPT na bateria de testes auditivos centrais foi útil nessa diferenciação.

RICCIO et al. ${ }^{60}, 1996$, investigaram a utilidade do ACPT no diagnóstico diferencial do TDAH em crianças com TPA. Avaliaram 30 crianças com o teste ACPT, metade com alteração de processamento auditivo e que se encaixavam nos critérios para TDAH do DSM-III e a outra metade com Transtorno do Processamento Auditivo e sem indícios de TDAH. Foi possível constatar que apesar de não ter sido observada diferença estatisticamente significativa entre os dois grupos, houve uma tendência do grupo com TPA/TDAH em demonstrar maior dificuldade no teste, quando comparado ao grupo com apenas TPA. Portanto, o ACPT é um teste limitado para diferenciar alterações do processamento auditivo e da atenção, sendo necessárias mais pesquisas na área para determinar os meios de diferenciar esses dois distúrbios ou determinar a possível existência de uma relação entre eles. 
FENIMAN ${ }^{16}, 1997$, conduziu um estudo com 18 crianças com idades entre seis e nove anos (média de 8,3 anos de idade), com diagnóstico primário de déficit de atenção e hiperatividade, utilizando o ACPT para avaliar a atenção auditiva sustentada. $\mathrm{O}$ autor verificou que apenas duas dessas crianças falharam nesse teste, atribuindo esse resultado ao efeito do uso de medicação, uma vez que era esperado um número maior de crianças com falha na atenção auditiva sustentada.

O Teste de Atenção Auditiva FC2, atualmente denominado THAAS, é um método de informação objetiva para descrever o comportamento de atenção auditiva em crianças, podendo fornecer informações que determinam se o problema de atenção existente é um fator que contribui para o problema de aprendizagem ou não. É utilizado para avaliar a atenção auditiva, verificando a habilidade da criança em escutar estímulos auditivos durante um período de tempo prolongado e responder somente para um estímulo específico. É uma tarefa de vigilância auditiva que serve para medir a atenção da criança, indicada pelas respostas corretas para as pistas lingüísticas específicas, e para medir a atenção sustentada, indicada pela habilidade da criança em manter a atenção e concentração na tarefa por um período de tempo prolongado. $O$ teste foi desenvolvido e aplicado em 280 crianças, entre seis e 11 anos de idade, por FENIMAN ${ }^{17}$, 2004. A autora observou que: a) crianças menores demonstravam maior número de erros de desatenção e de impulsividade do que as de maior idade, evidenciando que os escores do teste são altamente correlacionados com a idade do indivíduo; e, ${ }^{\text {b) }}$ a habilidade para sustentar a atenção deteriorou com o tempo da tarefa para todo o grupo 


\section{REVISÃo dA LITERATURA}

amostrado. Concluiu que o teste de atenção auditiva FC2 é altamente sugestivo para a identificação de problemas de atenção auditiva.

STOLLMAN et al. ${ }^{74}, 2004$, descreveram o desenvolvimento e resultados de uma bateria de testes para avaliação do processamento auditivo de crianças de 4 a 6 anos. Os testes foram aplicados em 28 crianças e dentre os testes escolhidos encontra-se o teste SAA (Sustained Auditory Attention), baseado no ACPT de KEITH ${ }^{38}$, 1994, e um Teste Dicótico Consoante-Vogal (etapa de atenção dividida). Os resultados mostraram que ambos os testes são adequados para a idade estudada e têm suas performances melhoradas com o aumento da idade. Os autores concluíram que a bateria de testes escolhida é adequada para avaliação do processamento auditivo de crianças de quatro anos ou mais e que novos estudos devem ser realizados com maior número de participantes, para padronização dos resultados.

\subsection{Teste Dicótico de Dígitos}

PEREIRA $^{58}$, 2004, relatou que é possível compreender as competências, capacidades e habilidades em lidar com sons observando-se os comportamentos reativos de crianças e adultos de diferentes faixas etárias em diversas tarefas, tal como aquelas que se sobrepõem no tempo e são apresentadas para ambas as orelhas (tarefa de escuta dicótica). Mencionou ainda que entre os mecanismos fisiológicos auditivos de reconhecimento dos sons verbais em escuta dicótica - habilidade auditiva de figura-fundo para sons 
verbais em processo de atenção sustentada - podem ser observados os comportamentos reativos ao Teste Dicótico de Dígitos-etapa de atenção direcionada à direita e à esquerda.

KIMURA $^{39,40}, 1963 ; 1967$, observou predominância de vantagem da orelha direita no reconhecimento de pares de dígitos, especialmente em indivíduos com representação lingüística no hemisfério esquerdo. A autora explicou que ocorre domínio do sistema auditivo contralateral em tarefas dicóticas, com supressão da via homolateral. A informação que chega da orelha ipsilateral ao hemisfério dominante para representação lingüística é atenuada ao atravessar o corpo caloso.

GEFFEN $^{20}$, 1978, avaliou 48 crianças, com idades entre seis e 10 anos, com testes dicóticos com um, dois, três e quatro pares de dígitos em etapa de atenção direcionada. Os resultados mostraram que não houve diferenças entre os gêneros. Vantagem para a orelha direita foi observada em todas as idades e a habilidade de direcionar a atenção para a orelha esquerda aumentou entre as idades de seis e oito anos.

JÄNCKE; STEINMETZ; VOLKMANN ${ }^{35}$, 1992, utilizaram sete testes dicóticos, incluindo direcionar a atenção para a orelha direita e esquerda com estímulo consoante-vogal para verificar a lateralização auditiva em adultos jovens, 26 destros e 26 canhotos. Os resultados mostraram que diferentes tarefas dicóticas revelam diferentes resultados e que a dominância hemisférica para linguagem não pôde ser concluída com os testes utilizados.

HISCOCK; CHIPUER ${ }^{29}$, 1993, realizaram três diferentes experimentos para analisar o efeito priming na mudança do direcionamento da 


\section{REVISÃo dA LITERATURA}

atenção de uma orelha para a outra. No primeiro experimento, as autoras realizaram um teste dicótico com dígitos, com atenção direcionada, em 30 crianças com idade entre cinco e oito anos e observaram um forte efeito de priming, ou seja, o desempenho, quando a atenção foi direcionada para a segunda orelha a ser testada, foi prejudicado pela atenção despendida na primeira orelha. Sugeriram que mudar a atenção da orelha direita para a esquerda não é mais difícil do que mudar a atenção da esquerda para a direita, mas que a orelha esquerda parece ser mais susceptível à ordem do direcionamento da atenção. No segundo experimento, foram utilizados os dígitos do canal A para serem apresentados de forma monoaural, com ruído competitivo ipsilateral, primeiramente em uma orelha e depois na outra. Foi possível observar que o desempenho da segunda orelha testada foi superior ao da primeira. No terceiro experimento, os dígitos de ambos os canais foram colocados na mesma orelha e foi possível observar que os resultados foram similares aos do segundo experimento. Portanto, selecionar a atenção para uma orelha não é suficiente para criar o efeito priming; aparentemente é necessário um sinal a ser rejeitado na orelha oposta, mostrando que a competição interaural é uma condição necessária para que ocorra o efeito priming.

ASBJORNSEN; HUGDAHL ${ }^{4}, 1995$, analisaram os efeitos da atenção na escuta dicótica em 62 adultos jovens. Foi aplicado o Teste Dicótico Consoante-Vogal, etapas de atenção direcionada à esquerda e à direita e atenção dividida. Ocorreu aumento da pontuação para a orelha solicitada e diminuição da pontuação da orelha não solicitada durante a etapa de atenção 
direcionada, ou seja, a vantagem da orelha mudou em conseqüência das instruções de direcionamento da atenção. Os indivíduos foram capazes de mudar uma vantagem da orelha direita, na etapa de atenção dividida, para uma vantagem da orelha esquerda na etapa de escuta direcionada para a esquerda. O direcionamento da vantagem para a orelha solicitada, durante a etapa de atenção direcionada, foi basicamente mediado pela supressão na intrusão de estímulos dados na orelha não solicitada e na facilitação para reportar-se à orelha solicitada.

ORTIZ ${ }^{56}, 1995$, analisou a atenção seletiva em tarefa de escuta dicótica, etapas de atenção livre e atenção direcionada, para estímulos verbais e não-verbais, em 80 adultos destros. A autora observou que não houve diferenças entre os gêneros e que houve predominância de vantagem para a orelha direita em ambos os testes.

SANTOS $^{66}, 1998$, estudou o desempenho de 140 indivíduos destros, com idades entre cinco e 25 anos, no Teste Dicótico de Dígitos, tanto na etapa de integração biaural quanto na de escuta direcionada para a direita e esquerda. Foi obtida porcentagem maior que 90 para o Índice de Reconhecimento de Dígitos, mostrando que o Teste Dicótico de Dígitos é um teste de fácil realização, podendo ser aplicado em indivíduos a partir dos cinco anos. Foi possível concluir que os indivíduos apresentaram vantagem da orelha direita nas duas etapas e que o desempenho no teste foi melhorando conforme a faixa etária aumentava.

ASBJORNSEN; BRYDEN³, 1998, compararam o desempenho de 19 crianças disléxicas com um grupo controle $(n=36)$, ambos formados por 


\section{REVISÃo dA LITERATURA}

crianças do gênero masculino, com idade entre nove e 14 anos, em um Teste Dicótico Consoante-Vogal, a fim de observar mudanças na atenção auditiva. Outros dois testes de atenção foram aplicados, a fim de realizar comparações. Os resultados mostraram que crianças disléxicas apresentam alterações na atenção auditiva quando comparadas a um grupo controle.

WELSH; ELLIOTT ${ }^{78}, 2001$, realizaram uma adaptação do Teste de Escuta Dicótica a fim de diminuir efeitos de atenção e memória. Nesse teste adaptado, os indivíduos recebiam a informação auditiva dicótica e deveriam mostrar o alvo o mais rápido que pudessem. Apresentaram vantagem para a orelha direita $93 \%$ da amostra de 28 indivíduos adultos.

HERTRICH et al. ${ }^{28}, 2002$, utilizaram a magnetoencephalography (MEG) com dois estímulos dicóticos consoante-vogal, um com fala natural e outro com fala sintética, para compreender se a resolução temporal e processos lingüísticos/fonéticos contribuem para a predominância do hemisfério esquerdo na decodificação de sílabas consoante-vogal. Os autores encontraram diferenças entre os gêneros apenas na tarefa com fala sintética, evidenciando-se que existem diferentes estratégias de processamento quando o estímulo é a fala natural e quando é artificial.

SOUZA; SOUZA ${ }^{71}, 2002$, descreveram o perfil do indivíduo com alteração no processamento auditivo, bem como as habilidades perceptuais envolvidas nesse processamento. Os autores ainda descreveram uma bateria de testes para a avaliação do processamento auditivo e quais as habilidades avaliadas em cada um dos testes. 
JOHNSEN et al $.^{36}, 2002$, estudaram o efeito da privação do sono numa tarefa de vigilância. Para tanto, o Teste Dicótico Consoante-Vogal foi aplicado em 12 indivíduos com privação do sono e 13 sem privação. Foi possível observar que ocorreu vantagem da orelha direita para os dois grupos tanto na etapa de integração biaural quanto na etapa de escuta direcionada à direita. Na etapa de escuta direcionada à esquerda, o grupo com privação do sono não mostrou vantagem de orelha, o que reflete uma diminuição na vigilância auditiva, uma vez que indivíduos com predominância do hemisfério esquerdo, naturalmente demonstram maior facilidade em identificar estímulos lingüísticos na orelha direita e necessitam de maior esforço cognitivo e atencional para identificar esses estímulos na orelha esquerda.

LIPSCHUTZ et al. ${ }^{44}, 2002$, estudaram as diferentes regiões cerebrais ativadas durante um Teste Dicótico Consoante-Vogal . Para tal, 10 indivíduos foram submetidos à tomografia computadorizada (PET). Os resultados mostraram que em tarefas de atenção auditiva ocorre ativação das regiões frontal, parietal e temporal. Em tarefas de atenção direcionada a uma orelha, a ativação ocorre principalmente em regiões do hemisfério contralateral ao lado atendido e, em tarefas de atenção dividida, a ativação ocorre em ambos os hemisférios. Portanto, os resultados deste estudo são consistentes com a idéia de uma rede multimodal da atenção em larga escala.

JÄNCKE et al. ${ }^{34}, 2003$, avaliaram nove indivíduos do gênero masculino com idades variando entre 21 e 27 anos, sem alterações neurológicas, em uma tarefa de escuta dicótica com tons de diferentes freqüências (não-lingüísticos) por meio de ressonância magnética funcional 


\section{REVISÃo dA LITERATURA}

(fMRI). Três tarefas dicóticas diferentes foram utilizadas: ${ }^{\text {a) }}$ prestar atenção nas informações dadas nas duas orelhas, ${ }^{\text {b) }}$ nas informações apenas da orelha direita ou da orelha esquerda $\mathrm{e}^{\mathrm{c})}$ monitorar um estímulo específico que poderia ser apresentado em qualquer uma das orelhas. Comparadas com o estado de repouso, todas as tarefas dicóticas ativaram regiões do córtex parietal, frontal e temporal. Ao comparar as tarefas entre si foi possível observar que, na tarefa de direcionar a atenção para os estímulos de uma determinada orelha, o planum temporale mostrou maior ativação.

SHINN et al. $.^{70}, 2005$, investigaram o efeito do direcionamento da atenção para a orelha direita e esquerda em dois testes dicóticos (dichotic consonant-vowel - DCV - e dichotic rhyme test - DRT). Participaram da pesquisa 20 adultos jovens, destros, com idade entre 20 e 27 anos (média de 22,5 anos) e com audição normal. Eles concluíram que o direcionamento da atenção durante o teste influenciou o desempenho de ambas as orelhas no DCV e que o DRT foi altamente resistente aos efeitos da atenção. Os autores ainda discutiram os diferentes mecanismos fisiológicos envolvidos e fizeram algumas considerações em relação à acústica dos dois testes, além de sugerirem o uso do DRT em complemento ao DCV, numa avaliação do processamento auditivo, nos casos em que há suspeita de déficit na atenção.

MUKARI et al. ${ }^{54}, 2006$, desenvolveram um Teste Dicótico de Dígitos para a língua utilizada na Malásia. Para tal, os autores aplicaram em 120 crianças, com idades entre seis e 11 anos (20 crianças em cada idade), o Teste Dicótico de Dígitos com apenas um par de dígitos e outro com dois pares, nas etapas de integração biaural e separação biaural para orelha direita 
e esquerda. Os resultados mostraram que o teste com dois pares de dígitos é melhor do que o teste com um par, pois ele produziu diferenças claras nos valores do teste entre as idades e permitiu uma padronização da pontuação em: normal, limítrofe e alterada.

MORTON; RAFTO, 2006, utilizaram a MRI em 113 indivíduos adultos durante tarefa dicótica consoante-vogal. O desempenho na tarefa dicótica não foi relacionado com o gênero ou dominância manual, e sim com a quantidade de fibras nervosas no corpo caloso.

\subsection{Atenção e Privação Sensorial}

FEAGANS $^{14}, 1987$, avaliou a atenção e as habilidades de narrativa de 44 crianças nas idades de cinco e sete anos, todas com histórico de otites de repetição nos três primeiros anos de vida. A atenção das crianças foi medida por meio de observação do comportamento em sala de aula. Os resultados indicaram que os processos atencionais podem ser mediadores entre as otites médias e futuros déficits de linguagem. A análise desse estudo mostra que existe uma correlação entre atenção, habilidades de parafrasear e OME, mas não se pode afirmar que esta relação é causal.

ARCIA; ROBERTS ${ }^{2}$, 1993, realizaram dois estudos para determinar a existência de associação entre repetidos episódios de OME durante a infância e alteração na atenção sustentada. No primeiro estudo, 70 crianças foram avaliadas por um psicólogo, que respondeu a um questionário sobre a 


\section{REVISÃo dA LITERATURA}

atenção destas crianças. No segundo estudo, foi aplicado um teste para avaliar a atenção sustentada por meio de tarefa visual. Os autores concluíram que a quantidade de episódios e duração das OME não estão associadas com a atenção sustentada.

FEAGANS; KIPP; BLOOD ${ }^{15}, 1994$, realizaram um estudo a fim de entender quando a otite média afeta a atenção para a linguagem em bebês de 12 a 18 meses de idade. Participaram da amostra 46 crianças, submetidas a sessões de leitura de livros ilustrados. As crianças foram divididas em dois grupos: com otite e com função da orelha média normal. Os resultados mostraram que as crianças com histórico de otite freqüente, durante um episódio de otite, tinham efeitos mais negativos em sua atenção. As mães de crianças com otites freqüentes relataram que seus filhos são mais distraídos e desatentos. Não existiu diferença na linguagem entre os grupos.

ROBERTS; BURCHINAL; CLARKE-KLEIN ${ }^{62}$, 1995, examinaram a associação entre OME durante os três primeiros anos de vida e o desempenho cognitivo e acadêmico, além de comportamentos, incluindo a atenção, em 56 crianças com 12 anos de idade. A avaliação constou de uma escala cognitiva, uma bateria de testes psico-educacionais e um questionário respondido pelos pais sobre comportamento. Os resultados mostraram que não houve relação entre OME nos primeiros anos de vida e a atenção e o desempenho acadêmico e cognitivo de crianças aos 12 anos de idade.

GRAVEL; WALLACE; RUBEN ${ }^{25}$, 1995, a fim de determinar a possíveis alterações em crianças de seis anos de idade, com e sem histórico de otites no primeiro ano de vida, aplicaram uma bateria de testes, padronizada 
para cognição e linguagem, em 14 crianças, além de solicitarem que os pais e professores respondessem a questionários sobre atenção, comportamento e desempenho na sala de aula. Os autores observaram que crianças com diminuição auditiva por OME no primeiro ano de vida apresentam risco para posterior dificuldade acadêmica, particularmente em áreas que dependem da atenção auditiva. Os autores também especularam que a otite afeta a acuidade auditiva e, como conseqüência, afeta a habilidade de atender e/ou processar informações auditivas, particularmente em situações com ruído competitivo.

ASBJORNSEN et al. ${ }^{5}, 2000$, utilizaram o Teste Dicótico ConsoanteVogal (etapas de atenção dividida e direcionada) e um teste de linguagem, para estudar o desempenho de um grupo de 19 crianças com histórico de otite média (tratadas com tubo de ventilação), idade média de nove anos, e compararam os resultados aos de um grupo controle. Os resultados mostraram que o grupo experimental não apresentou alterações de linguagem, mas, apresentou vantagem da orelha direita mais acentuada que o grupo controle. Os autores concluíram que o grupo com histórico de otite média apresentou um déficit na habilidade de sustentar e manter a atenção em eventos auditivos.

KLAUSEN et al. ${ }^{41}, 2000$, realizaram um estudo retrospectivo com 19 crianças com histórico de OME e 19 de um grupo controle, todas com nove anos de idade, a fim de verificar os efeitos, a longo prazo, da OME na articulação, em habilidades lingüísticas, na lateralidade da linguagem e em habilidades de atenção auditiva. Para este último, foi utilizado o Teste Dicótico Consoante-Vogal, considerado válido para avaliar a atenção auditiva seletiva do individuo. Os autores relatam que o grupo com histórico de otites 


\section{REVISÃo dA LITERATURA}

apresentou vantagem mais acentuada para a orelha direita, em relação ao grupo controle, apesar de a média de acertos no teste estar dentro dos padrões de normalidade para ambas as orelhas. Para os autores, a privação sensorial durante os primeiros anos de vida pode ter afetado o desenvolvimento do centro receptivo da linguagem, resultando numa área de processamento verbal maior e mais desenvolvida. Portanto, apesar de ser um estudo pequeno, os autores concluíram que a OME interfere na habilidade persistir e focar a atenção em eventos auditivos.

MINTER et al. ${ }^{50}, 2001$, examinaram se a OME associada à deficiência auditiva durante os quatro primeiros anos de vida está relacionada a informações sobre atenção, dadas por pais, professores e clínicos de crianças, nos primeiros seis anos de vida. Foram aplicados questionários sobre atenção com pais, professores e clínicos de 85 crianças, acompanhadas audiologicamente desde o sexto mês de vida. Os resultados indicaram que não houve relação estatisticamente significativa entre OME nos primeiros anos de vida e medidas de atenção aos seis anos de idade.

CAMPOS; CRUZ; FENIMAN ${ }^{10}$, 2002, aplicaram o teste PSI (Pediatric Speech Intelligibility Test), que avalia a habilidade de figura-fundo e atenção seletiva, em 12 crianças com fissura labiopalatina, com idades entre sete e 10 anos. Os resultados mostraram alteração no teste de $75 \%$ das crianças estudadas.

ROBERTS et al. ${ }^{61}, 2004$, realizaram uma revisão de literatura procurando uma ligação entre OME e audição periférica, habilidades do processamento auditivo, fala, linguagem, desempenho acadêmico e atenção. 
Os resultados indicam que não há conclusão evidente de que a OME afete o desempenho acadêmico, a atenção e o comportamento de crianças, em longo prazo.

MAHONE ${ }^{46}, 2005$, realizou uma revisão de literatura a fim de identificar e descrever métodos de avaliação da atenção em crianças préescolares, com idade inferior ou igual a seis anos. Entre os testes encontrados e descritos pelo autor, apenas um avaliava a atenção auditiva, o ACPT, utilizado para verificar a atenção auditiva sustentada. Além da validação do teste, o autor comparou os resultados do teste em crianças com função auditiva normal e crianças com $\mathrm{OME}$, e não encontrou diferenças entre os desempenhos dos dois grupos.

POPE; SNYDER ${ }^{59}$, 2005, examinaram as taxas de ajuste psicossocial para problemas e competências em crianças e adolescentes com fissura labiopalatina. Os pais de 724 crianças preencheram um questionário sobre comportamentos de seus filhos, que incluía a atenção. Os resultados sugeriram que crianças e adolescentes com FLP apresentavam altos riscos para desenvolver desajustes psicossociais, mas, muitos deles não apresentavam esses desajustes ao nível de tratamento clínico. Os problemas de atenção foram verificados, especialmente no gênero masculino, entre as idades de quatro e 18 anos e, no gênero feminino, entre quatro e 11 anos. 

3 犋 



\section{PROPOSIÇÃO}

A fissura labiopalatina é um indicador de risco para alterações de orelha média, o que pode prejudicar o desenvolvimento de habilidades auditivas tais como a atenção, que é essencial para o aprendizado de novas habilidades, comunicação oral e escrita. O estudo do processo atencional na população com fissura labiopalatina é algo recente e pouco explorado na literatura específica consultada, assim, este trabalho poderá contribuir com novos subsídios na área, uma vez que teve como objetivos:

1. verificar o desempenho de crianças com fissura labiopalatina em dois testes, o THAAS e o Teste Dicótico de Dígitos (etapa de escuta direcionada), que avaliaram processos de atenção auditiva;

2. comparar o resultado com um grupo sem fissura labiopalatina;

3. verificar a associação entre os dois testes aplicados. 



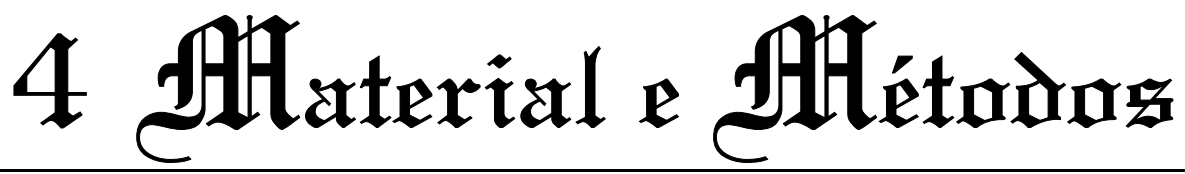





\section{MATERIAL E MÉTODOS}

\subsection{Casuística}

Fizeram parte deste estudo 55 crianças, de ambos os gêneros, na faixa etária de sete anos a sete anos e 11 meses, que foram distribuídas em dois grupos:

- G1: grupo controle, formado por crianças sem fissura labiopalatina;

- G2: grupo experimental, formado por crianças com fissura labiopalatina.

\subsubsection{Critérios de inclusão na amostra para o G1}

1. não apresentar fissura labiopalatina ou qualquer síndrome diagnosticada;

2. não apresentar diagnóstico de Transtorno do Déficit de Atenção e Hiperatividade (TDAH) ou tomar algum medicamento para tal transtorno;

3. ter audição periférica dentro dos padrões de normalidade;

4. ser destro;

5. não apresentar queixa e/ou alteração de processamento auditivo.

\subsubsection{Critérios para inclusão na amostra para o G2}

1. ser matriculado no Hospital de Reabilitação de Anomalias Craniofaciais (HRAC) e apresentar fissura labiopalatina 
transforame ou posforame (SPINA et al. $\left.{ }^{72}, 1972\right)$.

2. não apresentar diagnóstico de Transtorno do Déficit de Atenção e Hiperatividade (TDAH) ou tomar algum medicamento para tal transtorno;

3. ter audição periférica dentro dos padrões de normalidade;

4. ser destro;

5. não ter diagnóstico de qualquer tipo de síndrome.

\subsubsection{Procedimentos da Seleção}

O G1 foi obtido por meio de contato com duas escolas públicas da cidade de Bauru (SP). Foi enviada uma carta (Anexo 1) aos pais de todos os alunos matriculados na primeira série (190 alunos), explicando a importância desta pesquisa e solicitando que, aqueles que tivessem interesse que seu filho(a) participasse, preenchessem os dados solicitados (nome da criança, nome do responsável e telefone para contato). Em seguida, a própria pesquisadora entrou em contato, por telefone, com os pais, que devolveram a carta preenchida, e realizou os agendamentos. Foram respondidas 70 cartas e o contato telefônico foi realizado com todos. Destes, 15 ligações não puderam ser completadas em razão de o número do telefone estar incorreto ou o telefone estar fora de serviço ou ocupado, ou por não terem sido atendidas as ligações. Para cada criança agendada que não comparecia ao atendimento, um novo contato telefônico era realizado. No caso de nova falta, a criança foi automaticamente excluída do estudo e, assim, 11 crianças foram excluídas. As 
demais 44 compareceram ao atendimento; destas, 25 foram incluídas no G1. As demais 19 não se encaixavam nos critérios de inclusão do grupo.

Os responsáveis pelas crianças do $\mathrm{G} 1$ preencheram um questionário, pelo qual foi possível observar indicadores de risco para otites de repetição durante a infância (Anexo 2). Os indicadores de risco apresentados aos pais foram: histórico de refluxo gastroesofágico no primeiro ano de vida; histórico de infecções de vias aéreas superiores freqüentes até o terceiro ano de vida; histórico de otites freqüentes (três ou mais por ano) durante a infância; ter realizado cirurgia para colocação de tubo de ventilação. Por meio desse questionário, as crianças foram classificadas e se formaram dois subgrupos. 0 primeiro, com 10 crianças sem indicadores de risco para otites de repetição durante a infância e, o segundo, com 15 crianças que apresentavam esses indicadores.

Os dois grupos foram comparados por meio do modelo de Análise de Variância (ANOVA), tanto para o Teste Dicótico de Dígitos quanto para o THAAS, e não foi possível observar diferenças estatisticamente significativas entre os dois grupos, com $p=0,602$ e $p=0,367$, respectivamente. Desta forma, os dois grupos foram reunidos e os indicadores de risco não foram considerados variáveis significativas para a análise dos dados.

SAES; GOLDBERG; MANTOVANI ${ }^{65}$, 2005, relataram que existe associação positiva da ocorrência e recorrências de secreção de orelha média com o refluxo gastresofágico e as doenças das vias aéreas superiores durante os primeiro anos de vida. Apesar das indicações deste tipo de cirurgia serem controversas, os tubos de ventilação são indicados em casos de OME: quando 
o tratamento medicamentoso não foi efetivo, quando existe perda auditiva superior a $25 \mathrm{~dB}$ ou quando esta interfere no desenvolvimento de fala e linguagem ${ }^{1}$.

Os indicadores de risco para otites de repetição durante a infância foram obtidos por meio de questionário aplicado nos responsáveis pelas crianças. No entanto, BRODY et al. ${ }^{9}$, 1999, e STEWART et al. ${ }^{73}$, 1999, relataram que os pais não são capazes de identificar quando seus filhos estão com OME, uma vez que esta doença é silenciosa, não causando dor à criança. O que torna o relato dos pais um dado subjetivo e de baixa confiança.

Para a obtenção do G2, primeiramente foi providenciada uma lista, no Centro de Processamento de Dados (CPD), com todos os pacientes portadores de fissura de lábio e palato ou palato isolado, que tivessem consulta agendada no HRAC, entre os meses de janeiro e setembro de 2006, e com sete anos completos na data da consulta. Em seguida foi solicitado ao setor de agendamento que verificasse a possibilidade de encaixar no horário préexistente os procedimentos desta pesquisa. Assim, foi possível realizar o agendamento de 150 crianças. Destas, 30 faltaram, 90 foram excluídas da mostra com base nos critérios de inclusão no G2, restando 30 crianças regularmente matriculadas e diagnosticadas no HRAC como portadores de fissura de lábio e palato ou palato isolado, que foram incluídas no $\mathrm{G} 2$, sendo seis com fissura do tipo posforame e 24 transforame .

A Figura 1 apresenta a distribuição da amostra entre os grupos, segundo o gênero. 


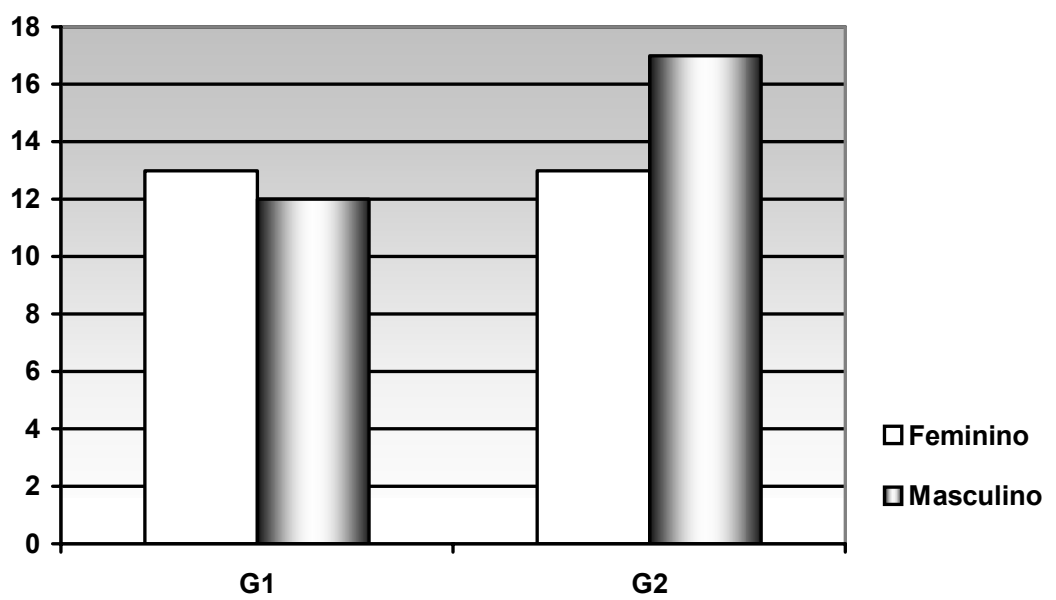

Figura 1 - Número de indivíduos em cada grupo distribuídos por gênero

\subsection{Método}

Este trabalho foi aprovado pelo Comitê de Ética em Pesquisa do HRAC, ofício número 233/2005 (Anexo 3).

Para ambos os grupos, o processo de avaliação constituiu da aplicação de um questionário (Anexo 2), que visou obter informações para inclusão ou não das crianças nos grupos, além de verificar a saúde auditiva e aspectos relacionados à habilidade de atenção da criança; bateria de testes auditivos convencionais; aplicação do Teste da Habilidade de Atenção Auditiva $(\text { THAAS })^{17}$ e do Teste Dicótico de Dígitos (etapa de escuta direcionada) ${ }^{67}$, com o objetivo de avaliar a habilidade de atenção auditiva. Todos os procedimentos foram realizados em um mesmo dia, sendo o THAAS realizado anteriormente ao Teste Dicótico de Dígitos.

A bateria de testes auditivos convencionais constituiu-se de: 
- audiometria tonal liminar, pela qual foram pesquisados os limiares auditivos das freqüências de 250, 500, 1 k, 2 k, 3 k, 4 k, $6 \mathrm{k} 8$ k Hz;

- imitanciometria, pela qual foram obtidos a curva timpanométrica com sonda de $226 \mathrm{~Hz}$ e os reflexos acústicos ipsilateral e contralateral das freqüências de 500, 1 k, 2 k e 4 k Hz.

Essa bateria de testes foi realizada anteriormente aos testes de atenção, para excluir indivíduos com perda de audição periférica e com função da orelha média alterada.

Os responsáveis pelas crianças participantes deste estudo assinaram um termo de consentimento livre e esclarecido (Anexo 4) após leitura da carta de informação (Anexo 5).

O THAAS consiste na apresentação diótica, por meio de fones de orelha, de uma lista de 21 palavras monossilábicas, na proporção de uma palavra por segundo, as quais são repetidas e rearranjadas aleatoriamente, formando uma lista de 100 palavras, incluindo as 20 ocorrências da palavra "não". Essa lista é apresentada seis vezes sem interrupção, totalizando 600 palavras durante todo o teste. As 21 palavras monossilábicas são: não (palavra-alvo), pé, sim, flor, gol, trem, mar, sol, quer, mal, lã, boi, meu, sal, pai, gás, vou, céu, já, pó e um. Cada criança foi instruída oralmente, pela avaliadora, de que iria ouvir uma lista de palavras e deveria levantar a mão toda vez que ouvisse a palavra não. Anteriormente à primeira apresentação, para treinamento, foi apresentada à criança uma amostra de 50 palavras 
monossilábicas sem interrupções, sendo 10 delas a palavra não, dispostas de maneira aleatória. O teste foi realizado somente após o entendimento da tarefa. As respostas das crianças foram marcadas, num protocolo de respostas (Anexo 6), com um xis ("X"), em frente a cada palavra do teste para a qual a criança levantou a mão. Este teste foi realizado em cabina acústica, com o auxílio de um CD player acoplado a um audiômetro (SD 50) de dois canais, a uma intensidade de 50 dBNS, considerando a média dos limiares aéreos auditivos para cada orelha, de maneira biaural e diótica.

O Teste Dicótico de Dígitos (etapa de escuta direcionada) consiste em quatro apresentações de uma lista de dígitos dissílabos do português brasileiro, em que quatro dígitos diferentes são apresentados simultaneamente, dois em cada orelha, caracterizando uma tarefa dicótica. A lista de dígitos (Anexo 7), elaborada por SANTOS; PEREIRA ${ }^{67}$, 1997, contém 40 pares arranjados aleatoriamente, totalizando 20 apresentações com dois pares em cada, um par em cada orelha. Os dígitos utilizados para formar a lista são o quatro, cinco, sete, oito e nove. Na primeira apresentação, a criança foi orientada a repetir os dígitos percebidos apenas na orelha direita (escuta direcionada para a direita). Na segunda apresentação, os dígitos identificados deveriam ser os percebidos apenas na orelha esquerda (escuta direcionada para a esquerda). Em seguida, o fone de orelha foi invertido e o teste foi repetido em ambas as orelhas. O teste foi aplicado por meio de um audiômetro de dois canais (SD 50), acoplado a um CD player, numa intensidade de 50 dBNS. 


\subsection{Análise dos Resultados}

Os dados foram analisados tendo em vista as respostas obtidas no THAAS e no Teste Dicótico de Dígitos (etapa de escuta direcionada).

O desempenho no THAAS foi obtido por meio de dois tipos de respostas da criança:

- erro de desatenção: quando a criança não levantou a mão em resposta à palavra-alvo (NÃO) antes da apresentação da palavra seguinte;

- erro de impulsividade: quando a criança levantou a mão para outra palavra ao invés da palavra NÃO.

Uma contagem do número de erros de desatenção acrescida do número de erros de impulsividade permitiu obter o total de erros no teste.

A vigilância foi obtida calculando-se o número de respostas corretas para a palavra NÃO para cada uma das seis apresentações da lista de palavras. O calculo dessa medida foi necessário, a fim de se verificar o decréscimo da vigilância, ou seja, o declínio na atenção que ocorreu com o tempo, durante a tarefa de vigilância. O decréscimo da vigilância ficou expresso calculando-se o número de respostas corretas para a palavra NÃO na primeira apresentação e o número de respostas corretas para a sexta apresentação. A diferença entre esses dois números encontrados é o que se denomina decréscimo da vigilância. 
No Teste Dicótico de Dígitos (etapa de escuta direcionada), os resultados obtidos foram registrados numa folha de marcação que contém as quatro listas que compõem o teste. O dígito identificado corretamente foi assinalado com um círculo. A seguir foi computado o número de acertos da orelha direita e da orelha esquerda.

\subsubsection{Análise estatística}

Os testes estatísticos* utilizados foram:

- Análise de Variância (ANOVA) com dois fatores, a fim de verificar a associação entre os resultados do THAAS e as variáveis gênero e grupo; as comparações post hoc foram feitas utilizando-se a correção de Tukey;

- ANOVA com medidas repetidas com três fatores, para verificar associações entre os resultados do Teste Dicótico de Dígitos e as variáveis orelha, gênero e grupo, sendo orelha o fator de repetição;

- Modelo de regressão linear múltiplo, que foi utilizado para verificar associações entre o THAAS e o Teste Dicótico de Dígitos; para se chegar ao modelo final foi utilizado o método de backward.

Considerou-se a diferença estatisticamente significativa quando $p \leq 0,05$.

\footnotetext{
* Para consultar maiores informações sobre os testes estatísticos verificar NETER et al. ${ }^{55}$, 1996.
} 

$5 \mathfrak{h}$ 



\section{RESULTADOS}

\subsection{THAAS}

O THAAS foi aplicado em todas as crianças participantes deste trabalho. Os resultados do teste THAAS dos dois grupos estão descritos na Tabela 1.

Tabela 1 - Valores de média, desvio-padrão, mínimo, mediana e máximo para as respostas do teste THAAS

\begin{tabular}{lccccccc}
\hline \multicolumn{1}{c}{ Variável resposta } & Grupo & N & Média & $\begin{array}{l}\text { Desvio- } \\
\text { padrão }\end{array}$ & Mínimo & Mediana & Máximo \\
\hline Desatenção & 1 & 25 & 14 & 12 & 0 & 13 & 39 \\
& 2 & 30 & 20 & 16 & 0 & 18 & 58 \\
Impulsividade & 1 & 25 & 4 & 4 & 0 & 3 & 14 \\
Total de Erros & 2 & 30 & 5 & 5 & 1 & 4 & 19 \\
Decréscimo da Vigilância & 1 & 25 & 18 & 13 & 3 & 21 & 53 \\
& 2 & 30 & 25 & 18 & 2 & 23 & 77 \\
& 1 & 15 & 2 & 3 & -3 & 4 & 8 \\
\hline
\end{tabular}

A média de cada resposta obtida com o THAAS, para os dois grupos, é apresentada na Figura 2.

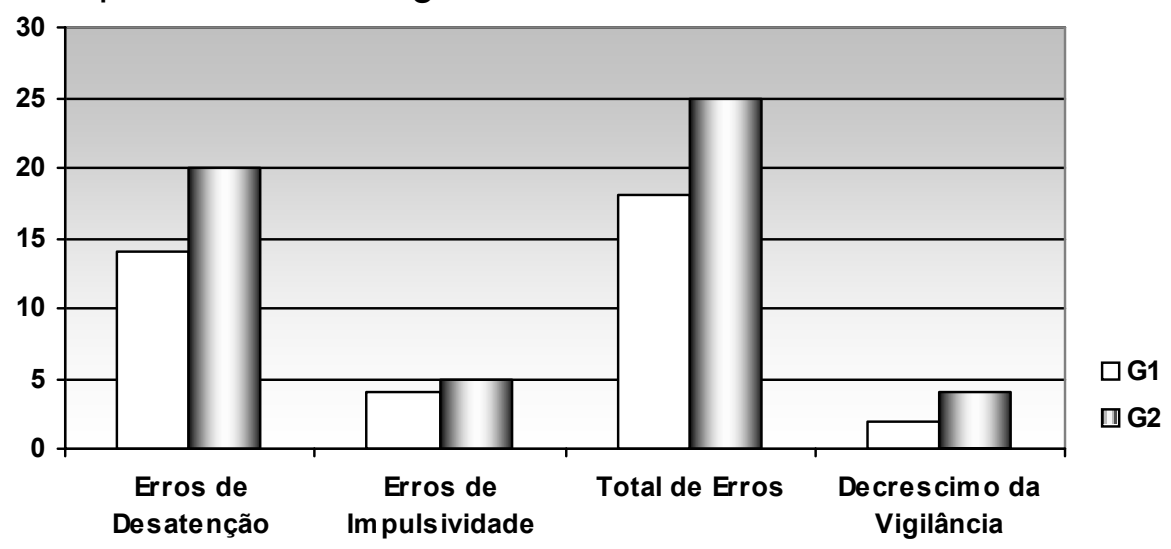

Figura 2 - Média dos valores do THAAS para os diferentes grupos estudados 
Para estudar a associação entre os resultados do THAAS e as variáveis grupo e gênero foi utilizado um modelo de análise de variância (ANOVA) com dois fatores. Na Tabela 2 é possível observar que houve associação estatisticamente significativa para o Decréscimo da Vigilância do THAAS e a variável grupo $(p=0,008)$. O grupo com fissura labiopalatina apresentou média 2,5 unidades maior que o grupo controle, esta diferença encontra-se entre 0,7 e 4,4 com $95 \%$ de confiança.

Tabela 2 - Análise de variância com 2 fatores das variáveis do teste THAAS

\begin{tabular}{ccccc}
\hline Fator & Desatenção & Impulsividade & Total de erros & $\begin{array}{c}\text { Decréscimo da } \\
\text { Vigilância }\end{array}$ \\
\hline Grupo & 0,100 & 0,454 & 0,100 & $0,008^{*}$ \\
Gênero & 0,720 & 0,623 & 0,653 & 0,689 \\
Grupo*Gênero & 0,619 & 0,494 & 0,807 & 0,462 \\
\hline
\end{tabular}

\section{2 - Dicótico de Dígitos}

O teste Dicótico de Dígitos (etapa de escuta direcionada) foi realizado em 52 das 55 crianças participantes do estudo.

Os resultados da orelha direita e orelha esquerda dos dois grupos amostrados estão descritos na Tabela 3. 
5 Resultados

Tabela 3 - Valores de média, desvio-padrão, mínimo, mediana e máximo para a orelha direita e esquerda no teste Dicótico de Dígitos

\begin{tabular}{cccccccc}
\hline $\begin{array}{c}\text { Variável } \\
\text { resposta }\end{array}$ & Grupo & N & Média & Desvio-padrão & Mínimo & Mediana & Máximo \\
\hline Orelha Direita & 1 & 22 & 90,85 & 7,76 & 75,00 & 90,00 & 100,00 \\
& 2 & 30 & 82,75 & 12,57 & 46,25 & 86,88 & 98,75 \\
Orelha & 1 & 22 & 87,90 & 7,04 & 75,00 & 87,50 & 97,50 \\
Esquerda & 2 & 30,00 & 79,96 & 11,86 & 52,50 & 78,75 & 98,75 \\
\hline
\end{tabular}

É possível observar na Figura 3 a média da porcentagem de acertos no teste Dicótico de Dígitos, para cada orelha, em cada grupo estudado.

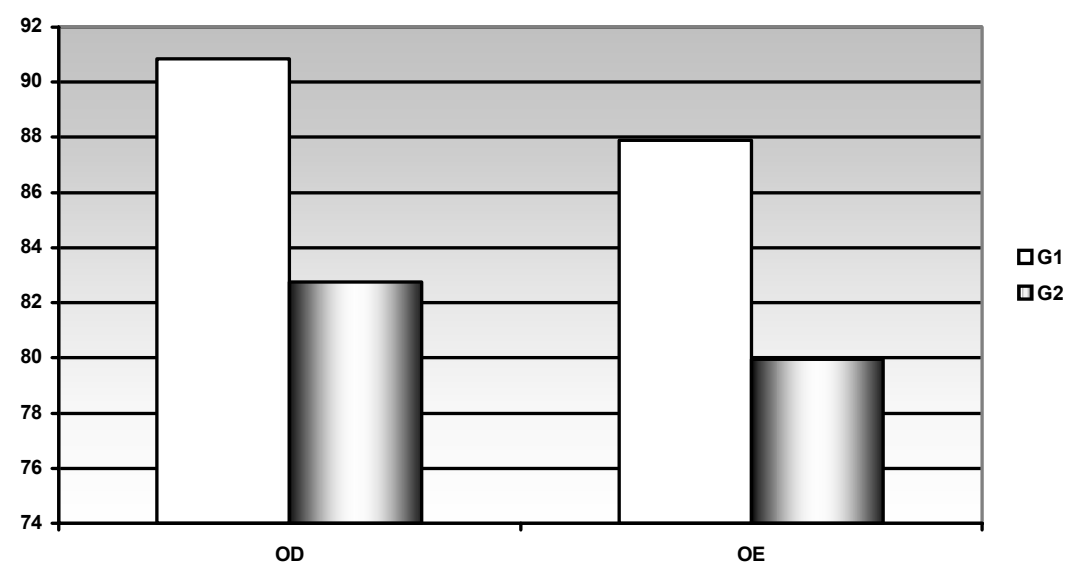

Figura 3 - Porcentagem de acertos no teste Dicótico de Dígitos para a orelha direita (OD) e para a orelha esquerda $(\mathrm{OE})$ nos dois grupos

O modelo de análise de variância com medidas repetidas com três fatores (grupo, gênero e orelha), sendo o fator orelha o fator de repetição, foi utilizado para verificar as associações do teste Dicótico de Dígitos. A Tabela 4 mostra que foi encontrada interação estatisticamente significativa entre Grupo e Gênero $(p=0,026)$. 
Tabela 4 - Análise de variância com medidas repetidas para o teste Dicótico de Dígitos

\begin{tabular}{cc}
\hline Fatores & $\mathbf{p}$ \\
\hline Grupo & $0,001^{*}$ \\
Gênero & 0,160 \\
Orelha & 0,078 \\
Gênero*Grupo & $0,026^{*}$ \\
Grupo*Orelha & 0,891 \\
Gênero*Orelha & 0,627 \\
Gênero*Grupo*Orelha & 0,593 \\
\hline
\end{tabular}

Para fazer as comparações post hoc, foi utilizada a correção de Bonferroni (NETER et al. ${ }^{55}$, 1996). Observando os resultados da Tabela 5, é possível verificar que o grupo controle apresentou média estatisticamente maior que o grupo com fissura labiopalatina $(p<0,0001)$, ao se considerar 0 gênero feminino, e também se constata que o gênero masculino apresentou diferença estatística significativamente maior que o gênero feminino, no grupo com fissura labiopalatina $(p=0,0059)$.

Tabela 5: Comparações post hoc da análise de variância com medidas repetidas

\begin{tabular}{|c|c|c|c|c|c|c|c|c|}
\hline \multirow{2}{*}{\multicolumn{2}{|c|}{ Diferença Estimativa }} & \multirow{2}{*}{$\begin{array}{l}\text { Erro- } \\
\text { padrão }\end{array}$} & \multirow{2}{*}{ gl } & \multirow{2}{*}{$t$} & \multirow{2}{*}{$\mathbf{p}$} & \multirow{2}{*}{ ns *. } & \multicolumn{2}{|c|}{$\begin{array}{c}\text { Intervalo de confiança } \\
(95 \%)^{* *}\end{array}$} \\
\hline & & & & & & & Limite inferior & $\begin{array}{l}\text { Limite } \\
\text { superior }\end{array}$ \\
\hline g1-g2 M & 3,2 & 3,3 & 48 & 0,96 & 0,3431 & 0,0125 & $-5,4$ & 11,7 \\
\hline g1-g2 F & 13,7 & 3,1 & 48 & 4,35 & $<0,0001^{*}$ & 0,0125 & 5,5 & 21,8 \\
\hline M-F g1 & $-2,0$ & 3,5 & 48 & $-0,58$ & 0,5674 & 0,0125 & $-11,0$ & 7,0 \\
\hline M-F g2 & 8,5 & 2,9 & 48 & 2,88 & $0,0059^{*}$ & 0,0125 & 0,8 & 16,1 \\
\hline
\end{tabular}

* nível de significância adotado considerando a correção de Bonferroni

** intervalo de confiança ajustado segundo a correção de Bonferroni 


\subsection{THAAS X Dicótico de Dígitos}

Para estudar a associação entre os testes, foram selecionados os resultados de total de erros (somatória dos erros de desatenção e impulsividade) e decréscimo da vigilância no THAAS; e orelha direita e orelha esquerda no Dicótico de Dígitos (etapa de escuta direcionada). Para tanto foi utilizado um modelo de regressão linear múltiplo e o método para se chegar ao modelo final foi o backward.

Na Tabela 6 observa-se que houve associação entre o total de erros do THAAS e os resultados da orelha direita do Dicótico de Dígitos $(p=0,00)$, apesar de essa associação ser considerada muito fraca, pois o $\mathrm{R}^{2}$ está abaixo de $0,30\left(R^{2}=0,24\right)$. Também houve associação estatisticamente significativa entre o decréscimo da vigilância do THAAS e a orelha direita e esquerda do Dicótico de Dígitos, esta também considerada muito fraca $\left(R^{2}=0,27\right)$.

Tabela 6 - Modelos de regressão finais para o total de erros e decréscimo da vigilância do teste THAAS

\begin{tabular}{ccccccc}
\hline Variável & \multicolumn{2}{c}{ Coeficientes } & Erro-padrão & $\mathbf{t}$ & $\mathbf{p}$ & $\mathbf{R}^{2}$ ajustado \\
\hline \multirow{2}{*}{ Total de erros } & Intercepto & 84,10 & 15,09 & 5,57 & $0,000^{*}$ & 0,24 \\
& OD DD & $-0,72$ & 0,17 & $-4,13$ & $0,000^{*}$ & \\
& Intercepto & 21,05 & 3,86 & 5,46 & $0,000^{*}$ & \\
Decréscimo da Vigilância & OD DD & $-0,08$ & 0,04 & $-2,00$ & $0,051^{*}$ & 0,27 \\
& OE DD & $-0,12$ & 0,04 & $-2,82$ & $0,007^{*}$ & \\
\hline
\end{tabular}



$\mathfrak{G}$ 㽞 



\section{DISCUSSÃO}

No presente estudo foi possível observar que o desempenho do grupo com fissura labiopalatina (G2) foi inferior ao do grupo controle em todos os tipos de resposta do THAAS (Figura 2). As crianças com fissura labiopalatina* apresentam longos períodos de privação sensorial por causa de alterações de orelha média ${ }^{12,24,27,30,77}$, o que pode levar a alterações no processamento auditivo $0^{6,8,11,13,49,}$ e poderia ser o fator causal da habilidade de atenção auditiva sustentada menos eficiente.

A atenção envolve tanto processos voluntários quanto reflexos, além de mecanismos guiados por estímulos que estão em competição dinâmica pelo controle do foco momentâneo da atenção ${ }^{19}$. Durante uma tarefa estruturada, na qual o individuo é solicitado a manter sua atenção em determinado alvo, como no THAAS, isso requer um processo voluntário de atenção.

É possível observar o desenvolvimento de habilidades mentais correlacionando-se a maturação de funções cognitivas específicas com um estágio particular de desenvolvimento neural, ou ainda, pode-se elucidar 0 papel da experiência ao moldar a mente e o cérebro $^{19}$. A experiência desempenha um papel crítico no crescimento final e na sincronização precisa dos circuitos neurais no cérebro ${ }^{76}$. Durante o desenvolvimento do sistema nervoso, períodos críticos são cruciais para resultados normais e podem ser considerados o tempo no qual os neurônios competem pelos sítios sinápticos;

\footnotetext{
" O termo fissura labiopalatina refere-se à fissura de lábio e palato ou apenas de palato.
} 
desse modo, o sistema nervoso otimiza as conexões neurais durante este período $^{45}$. Portanto, o desenvolvimento da atenção depende da recepção de estímulos, especialmente visuais e auditivos, referindo-se ao aprendizado de novas habilidades relacionadas à linguagem.

Mudanças na amplitude do estímulo no tímpano irão alterar as taxas de disparos dos neurônios ${ }^{19}$, o que mostra intensa relação entre a percepção do estímulo auditivo e o desenvolvimento da atenção auditiva. Assim, pode-se inferir que a privação sensorial causada por infecções de orelha média pode interferir no desenvolvimento da atenção auditiva de um indivíduo. Para HUGDAHL et al. ${ }^{32}, 2000$, a atenção tem efeito facilitador no processamento da audição.

É comum que o desempenho em um teste de atenção auditiva sustentada seja menor ao final da prova, em comparação ao seu início ${ }^{17}$. Na Tabela 2 pode-se notar que houve diferença estatisticamente significativa entre as crianças com fissura labiopalatina e o grupo controle no decréscimo da vigilância $(p=0,014)$, o que significa que enquanto as crianças do grupo controle apresentam decréscimo da vigilância de um (1) ponto, aquelas com fissura labiopalatina decrescem 2,5 pontos em sua vigilância. No trabalho de $\mathrm{KEITH}^{38}$, 1994, as crianças sem déficit de atenção e hiperatividade tinham menor declínio na atenção durante a tarefa de vigilância, quando comparadas às crianças com déficit de atenção e hiperatividade, o que evidencia que as crianças com fissura labiopalatina apresentam comportamento de decréscimo da vigilância semelhante àquelas com déficit na atenção e hiperatividade. 
A comparação dos resultados deste trabalho com os demais da literatura deve ser cautelosa, uma vez que, na literatura, pode-se observar diversos instrumentos que avaliam a atenção por meio de diferentes modalidades (auditiva e visual). O tipo de atenção avaliada nem sempre é especificado e ocorre por meio de avaliação de comportamentos da criança ${ }^{14,15,25,50,59,62}$, enquanto outros estudos utilizam testes específicos e avaliam um determinado tipo de atenção ${ }^{2,5,10,41}$.

Problemas de atenção foram relatados na população com alteração de leitura ${ }^{42}$, dislexia ${ }^{3}$, afasia ${ }^{43}$, esclerose ${ }^{69}$, TDAH $^{16}$, TPA $^{60}$, privação do sono ${ }^{36}$ e FLP ${ }^{10,59}$.

Como não foram encontrados trabalhos que relacionassem a atenção auditiva sustentada e a fissura labiopalatina, procurou-se correlacionar o presente estudo com aqueles que envolvessem populações com histórico de otites recorrentes ${ }^{12,24,27,30,77}$, ainda que, esses estudos estejam sujeitos a problemas metodológicos, incluindo estudos retrospectivos, que são cercados por vieses e métodos imprecisos de detecção da $O M E^{60,61}$. A OME, por ter caráter silencioso em mais de $50 \%$ dos episódios, torna seu estudo difícil, uma vez que sua documentação requer vigilância médica cuidadosa, independentemente dos sintomas ${ }^{14,15}$.

Neste estudo, a média do decréscimo da vigilância no grupo controle foi 2, próximo ao encontrado por FENIMAN ${ }^{17}, 2004$, na padronização do THAAS, que foi 1,5. O grupo com fissura labiopalatina apresentou média 4 no decréscimo da vigilância, inferior em comparação ao grupo controle deste estudo e ao trabalho de FENIMAN $^{17}, 2004$. 
Em concordância com o presente estudo, ASBJORNSEN et al. ${ }^{5}$, 2000, utilizaram um Teste Dicótico Consoante-Vogal e verificaram que o grupo com histórico de otite média apresentou um déficit na habilidade de sustentar e manter a atenção em eventos auditivos. KLAUSEN et al. ${ }^{41}, 2000$, também utilizando um Teste Dicótico Consoante-Vogal, concluíram que a OME interfere na habilidade de persistir e focar a atenção em eventos auditivos.

Com resultados divergentes daqueles encontrados no presente estudo, $\mathrm{MAHONE}^{46}, 2005$, utilizando um teste que avalia a atenção auditiva sustentada, semelhante ao THAAS, e com uma população de pré-escolares, não observou diferenças entre os desempenhos de crianças com e sem otites. ARCIA; ROBERTS ${ }^{2}, 1993$, utilizaram um teste que avalia a atenção auditiva sustentada visual e observaram que a quantidade de episódios e duração das OME não está associada com a atenção sustentada.

Ainda não existe um consenso a respeito do desempenho de crianças com histórico de otites durante a infância, em diversas áreas além da atenção, tais como linguagem, comportamento, acadêmica, cognitiva e processamento auditivo ${ }^{18,25,31,37,63,64,68,75}$. É importante ressaltar, porém, que as crianças com fissura labiopalatina apresentam períodos muito mais longos de privação sensorial, causados por infecções de orelha média, do que aquelas sem essa anomalia craniofacial. O que torna a população com fissura labiopalatina diferenciada neste aspecto.

No presente estudo não foi observada diferença estatisticamente significativa entre os gêneros (Tabela 2), concordando com os trabalhos de KEITH $^{38}$, 1994, e FENIMAN ${ }^{17}, 2004$. 
No Teste Dicótico de Dígitos (etapa de escuta direcionada), foi possível observar que o grupo com FLP apresentou porcentagens de acerto inferiores ao grupo controle, tanto para a orelha direita quanto para a orelha esquerda (Figura 3). A análise estatística mostrou interação estatisticamente significativa para grupo versus gênero, $p=0,026$ (Tabela 4), o que determinou a análise dos dados separada para cada gênero. Ao se considerar o gênero feminino, o grupo controle apresentou média estatisticamente maior do que o grupo com fissura labiopalatina $(p<0,0001)$ e, para o gênero masculino, não houve diferença estatisticamente significativa entre os grupos. No grupo com fissura labiopalatina, o gênero masculino apresentou diferença estatística significativamente maior que o gênero feminino $(p=0,0059)$ e, no grupo controle, essa diferença entre os gêneros não foi observada (Tabela 5).

Esses resultados mostram que as crianças do gênero feminino que apresentam fissura labiopalatina obtiveram baixo desempenho no Teste Dicótico de Dígitos. Na literatura estudada, não foi observada diferença entre os gêneros no número de acertos em testes dicóticos de dígitos com 1, 2, 3 e 4 pares ${ }^{20}$, em testes dicóticos não-verbal e consoante-vogal ${ }^{56}$. SANTOS ${ }^{66}, 1998$, utilizando o mesmo Teste Dicótico de Dígitos que o presente estudo, não encontrou diferenças entre os gêneros no grupo de crianças estudadas.

Opostamente ao encontrado nesta pesquisa, JÄNCKE; STEINMETZ; VOLKMANN $^{35}$, 1992, observaram uma tendência de indivíduos do gênero feminino terem pontuação melhor do que o masculino, em tarefa dicótica com consoantes e vogais. HERTRICH et al. ${ }^{28}, 2002$, observaram diferenças em 
relação ao gênero em Teste Dicótico Consoante-Vogal para estímulo sintético. Quando o estímulo era fala natural, não houve essa diferença.

Deve-se ter muita cautela ao se comparar diferentes testes dicóticos, uma vez que diferentes tarefas dicóticas revelam diferentes resultados ${ }^{35}$.

Parece existir uma tendência dos indivíduos do gênero masculino apresentarem maior vantagem para a orelha direita do que aqueles do gênero feminino ${ }^{28,78}$. No entanto, BELLIS; WILBER ${ }^{7}, 2001$, em seu estudo com Teste Dicótico de Dígitos em adultos, e ORTIZ ${ }^{56}$, 1995, com o Teste ConsoanteVogal e Não-Verbal, não revelaram essa tendência. Da mesma forma, o presente estudo demonstrou que o fator orelha não teve diferença estatisticamente significativa, $p=0,078$ (Tabela 4).

Para que aconteça um bom desempenho em tarefa dicótica lingüística, é necessário que informações atravessem o corpo caloso para atingirem o hemisfério de dominância para linguagem ${ }^{39,40}$. MORTON; RAFTO ${ }^{52}$, 2006, observaram que quanto maior o número de fibras nervosas no corpo caloso, melhor o desempenho em tarefas dicóticas com estímulo consoante vogal, não existindo associação com o gênero.

Neste estudo, a diferença encontrada entre os gêneros deve ser considerada com cuidado, uma vez que esse dado não é coerente com a literatura consultada e pode ser um resultado isolado. Neste caso, novos estudos devem ser realizados, a fim de determinar a influência do gênero na pontuação do Teste Dicótico de Dígitos.

Ao comparar o THAAS com o Teste Dicótico de Dígitos, foi possível observar que existe associação entre os testes, mas essa associação mostrou- 
6 DISCUSSÃo

se muito baixa (Tabela 6). O THAAS é um teste utilizado para avaliar a atenção auditiva sustentada ${ }^{17}$. O tipo de atenção requerida durante um teste dicótico é diversificado na literatura.

O individuo ter que direcionar e manter sua atenção nas informações dadas em uma orelha, enquanto ignora as informações da outra orelha, requer um processo de atenção auditiva seletiva ${ }^{29}$. No entanto, para PEREIRA ${ }^{58}$, 2004, ocorre um processo de atenção auditiva sustentada. Observando cuidadosamente a definição dada por GOMES et al. ${ }^{21}, 2000$, sobre os diferentes tipos de atenção auditiva, é possível compreender que os dois tipos de atenção auditiva, tanto a seletiva quanto a sustentada, podem estar envolvidas em uma tarefa dicótica na etapa de escuta direcionada. Cabe ressaltar que essa tarefa também envolve outras habilidades auditivas, como a de figura-fundo ${ }^{58,71}$.

Analisando alguns trabalhos que procuraram descrever as regiões cerebrais envolvidas em tarefas dicóticas, pode-se observar que ocorre ativação das regiões frontal, parietal e temporal ${ }^{34,44}$. Quando a tarefa dicótica exige direcionamento para uma das orelhas, ocorre ativação predominante da região temporal, especialmente do hemisfério contralateral ao lado atendido, tanto em tarefas dicóticas com um teste consoante-vogal ${ }^{44}$ como ao utilizar um teste dicótico com tons, não-lingüístico ${ }^{34}$.

A região cerebral ativa durante uma tarefa de atenção auditiva sustentada foi o giro cingulado, um feixe nervoso que liga os dois hemisférios cerebrais e faz parte do sistema límbico ${ }^{57}$. No entanto, são necessários estudos que determinem com maior clareza as regiões cerebrais responsáveis por cada 
tipo de atenção, sendo de consenso a existência de uma rede neural de larga escala, multimodal da atenção.

A baixa associação entre o THAAS e o Teste Dicótico de Dígitos, encontrada nesta pesquisa, pode reforçar a idéia de que o Teste Dicótico de Dígitos (etapa de escuta direcionada), envolve outros processos mentais e habilidades auditivas, que se sobrepõem à habilidade de atenção auditiva sustentada. No entanto generalizações devem ser feitas com cautela e novos estudos são necessários para melhor definir os processos envolvidos em cada tarefa. 


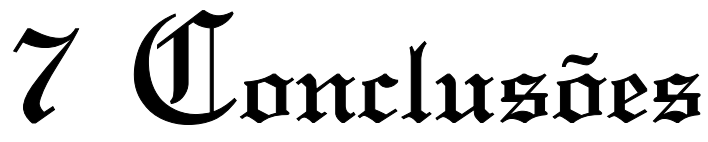





\section{CONCLUSÕES}

Os resultados obtidos com o presente trabalho permitiram concluir que:

- as crianças com fissura labiopalatina apresentaram desempenho no THAAS inferior àquelas sem essa anomalia craniofacial apenas para o decréscimo da vigilância;

- no Teste Dicótico de Dígitos (etapa de escuta direcionada), somente as crianças do gênero feminino com fissura labiopalatina obtiveram índices de acerto inferiores às do grupo controle;

- uma baixa associação foi verificada entre o THAAS e o Teste Dicótico de Dígitos (etapa de escuta direcionada), sugerindo que habilidades diferentes são responsáveis pelo desempenho nos dois testes. 

Anexus 



\section{Anexo 1}

\section{Carta aos pais}

Bauru, 14 de Agosto de 2006

Prezados Pais e/ou Responsáveis,

Viemos solicitar a sua colaboração para a realização de uma pesquisa relacionada à audição e atenção. Para tanto necessitamos de crianças de 7 anos que compareçam acompanhadas de 1 responsável ao Hospital de Reabilitação de Anomalias Craniofaciais (Centrinho) para aplicarmos tais testes.

Vale ressaltar que esta avaliação não causa nenhum tipo de desconforto ou dor à criança e tem duração média de $1: 30 \mathrm{~h}$.

Por meio destes testes será possivel verificar como e quanto a criança está ouvindo e prestando atenção.

Se você tem interesse em colaborar com esta pesquisa, que irá ajudar muitas crianças a terem um tratamento adequado para possíveis alterações, preencha abaixo e entraremos em contato em breve.

Qualquer duvida estamos a disposição para esclarecê-las no fone 30185571 (Isabel) ou 32241355 (Renata).

Obrigada pela atenção

Nome da Criança:

Nome do Responsável:

Telefone para contato:

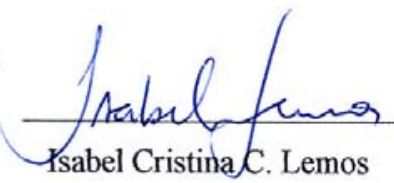

Fonoaudióloga

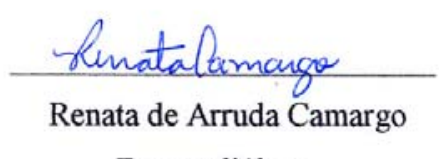

Fonoaudióloga

CRFa 14592

CRFa 8755 


\section{Anexo 2}

\section{Questionário}

\section{Parte I - IDENTIFICAÇÃO DA CRIANÇA}

Nome:

Prontuário:

Gênero:

Tipo de fissura: ( ) transforame bilateral

$$
\begin{aligned}
& \text { ( ) transforame unilateral ( ) direita ( ) esquerda } \\
& \text { ( ) posforame }
\end{aligned}
$$

Data de nascimento:

Idade: anos meses

Grau de escolaridade:

Tipo de escola: ( ) pública ( ) privada

Nível de instrução dos pais:

Nível sócio-econômico:

( ) destro ( ) canhoto ( ) ambidestro

\section{Parte II - ANTECEDENTES PESSOAIS E OBSTÉTRICOS}

Idade materna: $\quad$ Pré Natal: ( ) sim ( ) não

Idade gestacional: ( ) a termo ( ) pré-termo ( ) pós-termo

Doenças na gestação: ( ) sim ( ) não qual:

Medicamentos: ( ) sim ( ) não quais: época:

Drogas: ( ) $\operatorname{sim}$ ( ) não quais: época:

Álcool: ( ) sim ( ) não época:

Fumo: ( ) sim ( ) não época:

Raio X: ( ) sim ( ) não época:

Observação: 


\section{Parte III - CONDIÇÕES DA CRIANÇA}

Peso: Intercorrências: ( ) sim ( ) não qual:

Refluxo Gastresofágico: ( ) sim ( ) não quando:

Alergias: ( ) sim ( ) não

Doença da VAS: Outras Doenças:

\section{Parte IV - SAÚDE AUDITIVA}

História de perda auditiva. Orelha afetada:

( )OD

( )OE

História de infecções de ouvido. Qual orelha? Quantas vezes?

Cirurgia otológica: ( ) sim ( ) não qual:

Escuta bem: ambiente silencioso ( ) sim ( ) não ambiente ruidoso ( ) sim ( ) não

Dificuldade de conversação: ( ) em grupo ( ) com um interlocutor Localiza o som: ( ) sim ( ) não

Comportamento: ( ) muito agitado ( ) muito quieto

Boa compreensão: ( ) sim ( ) não

Tem dificuldade com: Fala ( ) sim ( ) não qual:

Escrita ( ) sim ( ) não qual:

Leitura ( ) sim ( ) não qual:

Outras ( ) sim ( ) não qual:

Teve dificuldade para aprender: Ler ( ) sim ( ) não qual:

Escrever ( ) sim ( ) não qual:

Repetência escolar: ( ) sim ( ) não qual série:

quantas vezes:

Demora para apresentar resposta: ( ) sim ( ) não 


\section{Anexo 3}

\section{Comitê de Ética}

Ofício n² 233/2005-UEP-CEP

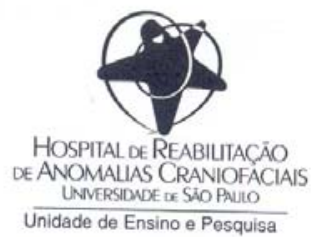

Bauru, 05 de agosto de 2005.

Prezado(a) Senhor(a)

O projeto de pesquisa encaminhado a este Comitê de Ética em Pesquisa em Seres Humanos, denominado "Aplicação do teste de atenção auditiva FC2 e do teste dicótico de dígitos em crianças com fissura labiopalatina: um estudo comparativo", de autoria de ISABEL CRISTINA CAVALCANTI LEMOS desenvolvido sob sua orientação, foi enviado ao relator para avaliação.

O parecer do relator, aprovando o projeto, foi aceito pelo Comitê, considerando que não existem infrações éticas pendentes para início da pesquisa. Solicitamos a V.Sa a gentileza de comunicar o parecer à pesquisadora.

A pesquisadora fica responsável pela entrega na Unidade de Ensino e Pesquisa dos relatórios semestrais, bem como comunicar ao CEP todas as alterações que possam ocorrer no projeto.

Informamos que após o recebimento do trabalho concluído, este Comitê enviará o parecer final para publicação.

\section{Atenciosamente}

PROF. DR. ROBERTO LOUREIRO MARINGONI

Coordenador do Comitê de Ética em Pesquisa do HRAC-USP

Ilmo(a) $\operatorname{Sr}(a)$

Profa. Dra. Mariza Ribeiro Feniman

Curso de Fonoaudiologia (Secretaria) - FOB/USP

rua Silvio Marchione, 3-20 Bauru SP Brasi caixa postal 1501 cep $17.012-900$ e-mail: e-mail: anag@usp.br 


\section{Anexo 4 \\ Termo de Consentimento Livre e Esclarecido}

$\mathrm{Eu}$ portador

de RG $n^{\circ}$

residente na rua

na

cidade de

Estado responsável pelo(a) menor*

matriculado no com o RG $n^{\circ}$ , após a leitura minuciosa da Carta de Informação ao Sujeito da Pesquisa, devidamente explicada pelos profissionais em seus mínimos detalhes, ciente dos serviços e procedimentos aos quais será submetido, não restando quaisquer duvida a respeito do lido e explicado, concordo em participar da (autorizo sua participação na)* pesquisa de título: "HABILIDADE DE ATENÇão AUDITIVA EM CRIANÇAS DE SETE ANOS COM FISSURA LABIOPALATINA: ESTUDO COMPARATIVO" realizada pela Fga. Isabel Cristina Cavalcanti Lemos, CRFa.14592, discente do curso de Mestrado em Fonoaudiologia da Faculdade de Odontologia de Bauru da Universidade de São Paulo, sob a orientação da Profa. Dra. Mariza Ribeiro Feniman.

A referida pesquisa tem como objetivo aplicar um questionário a vocês pais e/ou responsáveis por crianças sem e com fissura de lábio e/ou palato, visando verificar a história auditiva de seu filho(a), bem como os aspectos relacionados à atenção e realizar uma avaliação audiológica. O questionário, assim como os testes, deverão ser aplicados pela própria pesquisadora. Estes não promoverão desconforto e/ou risco para o informante nem para criança. 
ANEXO 4

É indiscutível a importância da participação de vocês pais e pacientes nessa pesquisa. Qualquer dúvida a respeito das perguntas constantes no questionário e/ou testes aplicados, bem como de assuntos relacionados ao estudo será esclarecida.

Ressaltamos que sua participação no estudo é inteiramente voluntária. A não aceitação em participar do mesmo, sem expor as razões, assim como, à desistência de sua participação a qualquer momento, não o prejudicará e nem comprometerá o tratamento do seu filho.

Sua identidade será mantida em sigilo. As informações obtidas no estudo serão divulgadas apenas na literatura especializada.

Estou ciente e de acordo com os termos de realização deste estudo, e autorizo por meio deste, a aplicação do questionário e a inclusão dos dados deste no presente estudo.

Bauru de de 200_.

Assinatura do paciente ou responsável ${ }^{*}$

${ }^{*}$ em caso de menor de idade
Assinatura da pesquisadora

Fga. Isabel Cristina C. Lemos

Nome do pesquisador responsável: Isabel Cristina Cavalcanti Lemos

Endereço Institucional: Alameda Octávio Pinheiro Brisolla 9-75

Cidade: Bauru

Estado: SP

CEP: $17012-910$

Telefone: (14) 235-8000

Ramal: 8232/8332/8556 


\section{Anexo 5 \\ Carta de Informação ao Sujeito da Pesquisa}

Considerando que o processo de atenção tem um profundo impacto social, na família, no trabalho e no ambiente escolar, quando se encontra alterado e, que a literatura específica consultada se mostra praticamente inexistente considerando esse processo na população com fissura labiopalatina, este trabalho tem como objetivo verificar o desempenho de crianças com essa anomalia craniofacial em dois testes que avaliam a atenção auditiva, o teste dicótico de dígito e o teste de atenção auditiva THAAS; comparar o resultado a de um grupo sem fissura labiopalatina e, verificar a relação entre os dois testes aplicados.

Para tanto serão realizadas, num mesmo dia, uma entrevista, avaliação auditiva básica e 2 testes para avaliação da atenção auditiva (THAAS e dicótico de dígitos), que terão duração média de 2 horas:

Entrevista: será aplicado um questionário a vocês pais e/ou responsáveis por crianças sem e com fissura de lábio e/ou palato, visando verificar a história auditiva de seu filho(a), bem como os aspectos relacionados à atenção.

Avaliação auditiva básica: audiometria - a criança deverá sentar-se com fones de ouvido dentro de uma cabina acústica, onde serão dados alguns sons e ela deverá levantar a mão sempre que escutá-los; imitanciometria - uma oliva (peça) de borracha será introduzida em seu conduto auditivo externo (orelha externa), não será necessário que a criança responda.

THAAS: a criança deverá sentar-se com fones de ouvido dentro de uma cabina acústica, um CD será tocado e a criança escutará algumas palavras. Será solicitado que a criança levante uma das mãos ao escutar a palavra "NÃO".

Dicótico de Dígitos: a criança deverá sentar-se com fones de ouvido dentro de uma cabina acústica, um CD será tocado e a criança escutará alguns números. Será solicitado que a criança repita o número que escutou.

Estes não promoverão desconforto e/ou risco para você (informante) nem para criança.

Os benefícios esperados com esta pesquisa são para a identificação de alteração na atenção auditiva de crianças no inicio da idade escolar, a fim de, futuramente ser possível prevenir as deficiências que esta alteração pode acarretar. 
Qualquer dúvida a respeito das perguntas constantes no questionário e/ou testes aplicados, bem como de assuntos relacionados ao estudo será esclarecida.

Caso seja observada qualquer tipo de alteração na atenção auditiva da criança, esta será encaminhada para o tratamento adequado.

Ressaltamos que sua participação no estudo é inteiramente voluntária. A não aceitação em participar do mesmo, sem expor as razões, assim como, à desistência de sua participação a qualquer momento, não o prejudicará e nem comprometerá o tratamento do seu filho.

Sua identidade será mantida em sigilo. As informações obtidas no estudo serão divulgadas apenas na literatura especializada.

"Caso o sujeito da pesquisa queira apresentar reclamações em relação a sua participação na pesquisa, poderá entrar em contato com o Comitê de Ética em Pesquisa em Seres Humanos, do HRAC-USP, pelo endereço Rua Silvio Marchione, 3-20 na Unidade de Ensino e Pesquisa ou pelo telefone (14) 3235-8421"

Bauru,

Nome do sujeito ou responsável:

Assinatura do sujeito ou responsável:

Nome do pesquisador responsável:

Assinatura do pesquisador responsável: 


\section{ANEXo 6}

\section{Teste de Atenção Auditiva - FC2}

Nome:

\begin{tabular}{|l|l|l|l|}
\hline \multicolumn{5}{|c|}{ Aprendizagem } \\
\hline & & & \\
\hline 1 & céu & 26 & céu \\
\hline 2 & pai & 27 & pai \\
\hline 3 & não & 28 & não \\
\hline 4 & flor & 29 & flor \\
\hline 5 & sol & 30 & sol \\
\hline 6 & não & 31 & não \\
\hline 7 & boi & 32 & boi \\
\hline 8 & quer & 33 & quer \\
\hline 9 & gás & 34 & gás \\
\hline 10 & não & 35 & não \\
\hline 11 & meu & 36 & meu \\
\hline 12 & sim & 37 & sim \\
\hline 13 & pé & 38 & pé \\
\hline 14 & mal & 39 & mal \\
\hline 15 & gol & 40 & gol \\
\hline 16 & não & 41 & não \\
\hline 17 & trem & 42 & trem \\
\hline 18 & lã & 43 & lã \\
\hline 19 & mar & 44 & mar \\
\hline 20 & não & 45 & não \\
\hline 21 & vou & 46 & vou \\
\hline 22 & já & 47 & já \\
\hline 23 & pó & 48 & pó \\
\hline 24 & sal & 49 & sal \\
\hline 25 & um & 50 & um \\
\hline & & & \\
\hline
\end{tabular}

\begin{tabular}{ll|l|l}
25 & um & 50 & um
\end{tabular}

\begin{tabular}{|l|l|l|l|l|l|l|l|}
\hline \multicolumn{7}{|c|}{ Apresentação } \\
\hline & & 1 & 2 & 3 & 4 & 5 & 6 \\
\hline 1 & pé & & & & & & \\
\hline 2 & sim & & & & & & \\
\hline 3 & flor & & & & & & \\
\hline 4 & gol & & & & & & \\
\hline 5 & não & & & & & & \\
\hline 6 & trem & & & & & & \\
\hline 7 & mar & & & & & & \\
\hline 8 & não & & & & & & \\
\hline 9 & sol & & & & & & \\
\hline 10 & quer & & & & & & \\
\hline 11 & mal & & & & & & \\
\hline 12 & lã & & & & & & \\
\hline 13 & boi & & & & & & \\
\hline 14 & meu & & & & & & \\
\hline 15 & não & & & & & & \\
\hline 16 & sal & & & & & & \\
\hline 17 & pai & & & & & & \\
\hline 18 & gás & & & & & & \\
\hline 19 & vou & & & & & & \\
\hline 20 & céu & & & & & & \\
\hline 21 & não & & & & & & \\
\hline 22 & já & & & & & & \\
\hline 23 & pó & & & & & & \\
\hline 24 & não & & & & & & \\
\hline 25 & um & & & & & & \\
\hline
\end{tabular}

Decréscimo de vigilância:
Idade:

Data:

\begin{tabular}{|l|l|l|l|l|l|l|l|}
\hline \multicolumn{7}{|c|}{ Apresentação } \\
\hline & & 1 & 2 & 3 & 4 & 5 & 6 \\
\hline 26 & lã & & & & & & \\
\hline 27 & boi & & & & & & \\
\hline 28 & sal & & & & & & \\
\hline 29 & não & & & & & & \\
\hline 30 & mal & & & & & & \\
\hline 31 & mar & & & & & & \\
\hline 32 & gol & & & & & & \\
\hline 33 & já & & & & & & \\
\hline 34 & não & & & & & & \\
\hline 35 & sim & & & & & & \\
\hline 36 & gás & & & & & & \\
\hline 37 & vou & & & & & & \\
\hline 38 & céu & & & & & & \\
\hline 39 & não & & & & & & \\
\hline 40 & quer & & & & & & \\
\hline 41 & trem & & & & & & \\
\hline 42 & não & & & & & & \\
\hline 43 & flor & & & & & & \\
\hline 44 & sol & & & & & & \\
\hline 45 & não & & & & & & \\
\hline 46 & pai & & & & & & \\
\hline 47 & pé & & & & & & \\
\hline 48 & meu & & & & & & \\
\hline 49 & pó & & & & & & \\
\hline 50 & um & & & & & & \\
\hline
\end{tabular}

Desatenção:

Resp. corretas na $1^{\text {a }}$ apres.:
Fga:

\begin{tabular}{|l|l|l|l|l|l|l|l|}
\hline \multicolumn{7}{|c|}{ Apresentação } \\
\hline & & & 2 & 3 & 4 & 5 & 6 \\
\hline 51 & flor & & & & & & \\
\hline 52 & lã & & & & & & \\
\hline 53 & mar & & & & & & \\
\hline 54 & não & & & & & & \\
\hline 55 & mal & & & & & & \\
\hline 56 & pai & & & & & & \\
\hline 57 & sim & & & & & & \\
\hline 58 & vou & & & & & & \\
\hline 59 & não & & & & & & \\
\hline 60 & pé & & & & & & \\
\hline 61 & meu & & & & & & \\
\hline 62 & boi & & & & & & \\
\hline 63 & não & & & & & & \\
\hline 64 & gol & & & & & & \\
\hline 65 & trem & & & & & & \\
\hline 66 & quer & & & & & & \\
\hline 67 & não & & & & & & \\
\hline 68 & sol & & & & & & \\
\hline 69 & já & & & & & & \\
\hline 70 & gás & & & & & & \\
\hline 71 & não & & & & & & \\
\hline 72 & sal & & & & & & \\
\hline 73 & pó & & & & & & \\
\hline 74 & céu & & & & & & \\
\hline 75 & um & & & & & & \\
\hline
\end{tabular}

Impulsividade:

\begin{tabular}{|c|c|c|c|c|c|c|c|}
\hline \multicolumn{8}{|c|}{ Apresentação } \\
\hline & & 1 & 2 & 3 & 4 & 5 & 6 \\
\hline 76 & Lã & & & & & & \\
\hline 77 & Mar & & & & & & \\
\hline 78 & Sal & & & & & & \\
\hline 79 & Não & & & & & & \\
\hline 80 & Flor & & & & & & \\
\hline 81 & Quer & & & & & & \\
\hline 82 & Não & & & & & & \\
\hline 83 & Gás & & & & & & \\
\hline 84 & Sim & & & & & & \\
\hline 85 & Mal & & & & & & \\
\hline 86 & Vou & & & & & & \\
\hline 87 & Meu & & & & & & \\
\hline 88 & Já & & & & & & \\
\hline 89 & Não & & & & & & \\
\hline 90 & Pai & & & & & & \\
\hline 91 & Não & & & & & & \\
\hline 92 & Pó & & & & & & \\
\hline 93 & Trem & & & & & & \\
\hline 94 & Pé & & & & & & \\
\hline 95 & Gol & & & & & & \\
\hline 96 & Sol & & & & & & \\
\hline 97 & Não & & & & & & \\
\hline 98 & Boi & & & & & & \\
\hline 99 & Céu & & & & & & \\
\hline 100 & um & & & & & & \\
\hline
\end{tabular}

Resp. corretas na $6^{\mathrm{a}}$ apres. : 
Anexo 7

\section{Lista de Dígitos}

\section{universiuaue ue sau rauio}

Faculdade de Odontologia de Bauru

Al. Dr. Octávio Pinheiro Brisolla, 9.75 - Bauru-SP - CEP 17012-901 - C.P. 73

PABX (0XX14)235-8000 - FAX (0XX14)223-4679

Clínica de Fonoaudiologia

Telefone: (0XX14) 235-8460

DÍGITOS DICÓTICOS

(Santos \& Pereira, 1997)

Nome: Idade

Data: I_ Responsável:

INTEGRAÇĀO BIAURAL

ATENÇÃO OD

ATENÇĀO OE

\begin{tabular}{|c|c|c|c|c|c|}
\hline D & E & D & E & D & E \\
\hline 5_4_ & 8_7 & 5_4 & 8_7 & 5_4_ & 8_7_ \\
\hline 4_8 & $9-7$ & 48 & 97 & 48 & $97^{-}$ \\
\hline $5+9$ & 84 & 59 & $8+4$ & 59 & $8+4$ \\
\hline 74 & 59 & 74 & $59-$ & 74 & 59 \\
\hline 98 & 75 & 988 & 75 & 98 & 75 \\
\hline 57 & $9-5$ & 57 & 95 & 57 & 95 \\
\hline 58 & 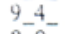 & 58 & $9-4$ & 58 & 94 \\
\hline $4-5-$ & $8-9-$ & $4 \_5$ & 89 & 4 & 89 \\
\hline $\begin{array}{l}4-9 \\
9\end{array}$ & $\frac{7-8}{4}-$ & 4_9 & 7_8 & 4_9- & 78 \\
\hline $4-$ & $\begin{array}{l}4-8 \\
8-5\end{array}$ & 95 & 4_8 & 9_5 & 48 \\
\hline 85 & 47 & $\frac{4}{8}-7-$ & $85-$ & $\begin{array}{l}4-7 \\
8-5-\end{array}$ & 85 \\
\hline 89 & $7{ }^{4}$ & $\begin{array}{l}8-5 \\
8-9\end{array}$ & $\begin{array}{l}4-7- \\
7-4\end{array}$ & $\begin{array}{l}8-5 \\
8-9\end{array}$ & ${ }^{4}-7-$ \\
\hline 79 & 58 & 79 & 58 & 79 & $5-8$ \\
\hline $9-7$ & $4-5$ & 97 & 45 & $97_{-}^{-}$ & $4-5$ \\
\hline 78 & 54 & $78-$ & $5=$ & 78 & 5 \\
\hline 7,5 & 98 & 75 & 98 & 75 & 98 \\
\hline $8-7$ & $4=9$ & $8-7-$ & 49 & $8-7$ & $49^{-}$ \\
\hline 9.4 & $5-7$ & 9_4_ & 57 & 94 & 57 \\
\hline 8_4_- & 7_9 & $8{ }^{4}{ }_{-}$ & 7_9 & 8.4 & 7_9_ \\
\hline E & D & E & D & E & D \\
\hline $5-4$ & 8_7 & 5_4- & 8_7- & 5.4 & $87_{-}$ \\
\hline 48 & 97 & 48 & 97 & 4_8 & $9-7$ \\
\hline $5-9$ & 8 -4 & 59 & 84 & 59 & $8+4$ \\
\hline $7-4$ & $5-9-$ & $7-4-$ & $59-$ & 74 & 59 \\
\hline $9-8$ & $7-5-$ & $9-8$ & 7_5- & $9{ }_{-}^{8}$ & $75_{-}$ \\
\hline $5-7-$ & $9-5-$ & $\begin{array}{l}5-7 \\
5-8\end{array}$ & $9-^{5}-$ & $5-7$ & 95 \\
\hline $5-8$ & $\begin{array}{l}9-4- \\
8-9-\end{array}$ & $\begin{array}{l}5-8 \\
4 \_5 \\
-5\end{array}$ & $\begin{array}{l}9.4- \\
8-9\end{array}$ & $5 \_8$ & 944 \\
\hline 49 & $7-8$ & $\begin{array}{l}4-5 \\
4 \_9-\end{array}$ & $\begin{array}{l}8-9 \\
7-8\end{array}$ & $4-5$ & 8_9- \\
\hline $9-5$ & 4_8- & 95 & $4-8$ & $\begin{array}{l}4-9 \\
9 \\
5\end{array}$ & $\begin{array}{l}7-8 \\
48\end{array}$ \\
\hline $4 \_7$ & $8{ }^{5}$ & $4 \_7$ & $8+5$ & $4-7$ & 85 \\
\hline $8 \leq 5$ & $4-7$ & 85 & $4-7$ & $8+5$ & $4-7$ \\
\hline 8_9- & $74-$ & $89-$ & 74 & 89 & $74_{-}^{-}$ \\
\hline 79 & 58 & 789 & 58 & 79 & 58 \\
\hline $97^{-}$ & $4 \_5$ & 9_7 & 4_5 & 97 & $4] 5$ \\
\hline 78 & 54 & $7-8$ & 5.4 & 7_8 & 54 \\
\hline 7_5 & 9_8 & 75 & 98 & $7-5$ & $9-8$ \\
\hline $8-7-$ & $\begin{array}{l}4-9 \\
57\end{array}$ & $8-7-$ & 4-9- & 8_7- & 4_9- \\
\hline $84^{-4}$ & $79-$ & $8-4$ & $79-$ & $\begin{array}{l}9-4 \\
9-4\end{array}$ & $\begin{array}{l}57 \\
5-7\end{array}$ \\
\hline
\end{tabular}

Integração Biaural: $\mathrm{OD} \_$_ $\%$ acertos $\mathrm{OE}$

Atenção Direcionada para Direita: $\mathrm{OD}$

$\%$ de acertos

Atenção Direcionada para Esquerda: OD 


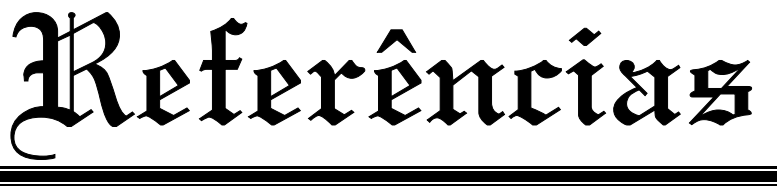





\section{REFERÊNCIAS}

1. Almeida CIR. Tubos de ventilação. In: CALDAS N, NETO SC, SIH T. Otologia e Audiologia em Pediatria. Rio de Janeiro: Revinter; 1999. p. 8593.

2. Arcia E, Roberts JE. Otitis media in earlu childhood and its association with sustained attention in structured situation. Dev Behav Pediat. 1993;14(3):181-3.

3. Asbjornsen AE, Bryden MP. Auditory attentional shifts in reading-disabled students: quantification of attentional effectiveness by the Attentional Shift Index. Neuropsychol. 1998;36(2):143-8.

4. Asbjornsen AE, Hugdahl K. Attentional effects in dichotic listening. Brain Lang. 1995;49:189-201.

5. Asbjornsen AE, Holmefjord A, Reisaeter S, Moller P, Klausen O, Prytz B et al. Lasting auditory attention impairment after persistent middle ear infections: a dichotic listening study. Develop Med Child Neurol. 2000;42:481-6.

6. Barufi L, Netto MP, Ulhôa FM, Rego CF, Feniman MR, Cruz MS et al. Comportamento de escuta em indivíduos com fissura labiopalatina: achados preliminares. J Bras Fonoaudiol. 2004;5(19):91-5.

7. Bellis TJ, Wilber LA. Effects of aging and gender in interhemispheric function. J Speech Lang Hear Res. 2001;44:246-63.

8. Belloni M, Santos MFC. Processamento auditivo em crianças com fissura labiopalatina não sindrômica. In: Anais do $20^{\circ}$ Encontro Internacional de Audiologia; 2005 abril; São Paulo, SP. [em CD-ROM].

9. Brody R, Rosenfeld RM, Goldsmith AJ, Madel JR. Parents cannot detect mild hearing loss in children. Otolaryngol Head Neck Sur. 1999;121(6):6816.

10. Campos CF, Cruz MS, Feniman MR. Habilidades auditivas de figura fundo e atenção seletiva em crianças portadoras de fissura labiopalatina. In: Anais do I Congresso Brasileiro de Fonoaudiologia e Genética dos Distúrbios da Comunicação; 2002; Fortaleza, CE. p. 44.

11. Cassab TV, Zorzetto NL. Teste da Fusão Auditiva-Revisado (AFT-R) em crianças com fissura labiopalatina. Acta AWHO. 2002;21(3).

12. Chu KM, McPherson B. Audiological status of Chinese patients with cleft lip/palate. Cleft Palate Craniofac J. 2005 May;42(3):280-5.

13. Cruz MS, Campos CF, Feniman MR. Desempenho da população com fissura labiopalatina no teste SSW. In: Anais da IX Jornada Fonoaudiológica da Faculdade de Odontologia de Bauru; 2002; Bauru, SP. p. 26.

14. Feagans $L$. Relationship of middle ear disease in early childhood to later narrative and attention skills. J Pediat Psychol. 1987;12(4):581-95. 
15. Feagans LV, Kipp E, Blood I. The effects of otitis media on the attention skills of day-care-attending toddlers. Dev Psychol. 1994;30(5):701-8.

16. Feniman MR. Central auditory processing disorder in attention deficit hyperactivity disorder, and language-based learning impairment: a normative study. [Tese]. Cincinnati (Ohio): Cincinnati University of Cincinnati; 1997.

17. Feniman MR. Aplicação do teste de atenção auditiva FC2 em crianças ouvintes normais. [Tese]. Bauru (SP): Faculdade de Odontologia de Bauru Universidade de São Paulo; 2004.

18. Fucci CRC, Faria KM, Paula PC. Pesquisa das habilidades auditivas comprometidas em crianças com história de otites médias recorrentes na infância. In: Anais do $20^{\circ}$ Encontro Internacional de Audiologia; 2005 abril; São Paulo, SP. [em CD-ROM].

19. Gazzaniga MS, Ivry RB, Mangun GR. Atenção seletiva e orientação. In: Gazzaniga MS, Ivry RB, Mangun GR. Neurociência cognitiva. Porto Alegre: Artmed; 2006. p.262-318.

20. Geffen $\mathrm{G}$. The development of the right ear advantage in dichotic listening with focused attention. Cortex. 1987;14:169-77.

21. Gomes H, Molholm S, Christodoulou C, Ritter W, Cowan N. The development of auditory attention in children. Front Biosci. 2000 Jan;1(5):D108-20.

22. Gonçales AS. Avaliação do desenvolvimento das habilidades auditivas durante o primeiro ano de vida. In: Aquino AMCM, org. Processamento auditivo: eletrofisiologia e psicoacústica. São Paulo: Lovise; 2002. p.111-20.

23. Gordon PC, Eberhardt JL, Rueckl JG. Attentional modulation of the phonetic significance of acoustic cues. Cogn Psychol. 1993;25:1-42.

24. Goudy S, Lott D, Canady J, Smith RJ. Conductive hearing loss and otopathology in cleft palate patients. Otolaryngol Head Neck Surg. 2006;134(6):946-8.

25. Gravel JS, WALLACE IF, RUBEN RJ. Early otitis media and latter educational risk. Acta Otolaryngol. 1995;115:279-81.

26. Gravel JS, Wallace IF, Ruben RJ. Auditory consequences of early middle hearing loss associated with otitis media. Acta Otolaryngol. 1996;116:21921.

27. Handzic-Cuk J, Cuk V, Gluhinic M, Risavi R, Stajner-Katusic S. Tympanometric findings in cleft palate patients: influence of age and cleft type. J Laryngol Otol. 2001 Feb;115(2):91-6.

28. Hertrich I, Mathiak K, Lutzenberger W, Ackermann H. Hemisferic lateralization of the processing of consonant-vowel syllables (formant transitions): effects of stimulus characteristics and attentional demands on evoked magnetic fields. Neuropsychol. 2002;40:1902-17. 
29. Hiscock M, Chipuer H. Children's ability to shift attention from one ear to the other: divergent results for dichotic and monaural stimuli. Neuropsychol. 1993;31(12):1339-50.

30. Hocevar-Boltezar I, Jarc A, Kozelj V. Ear, nose and voice problems in children with orofacial clefts. J Laryngol Otol. 2006;120(4):276-81.

31. Hogan SC, Moore DR. Impaired binaural hearing in children produced by a threshold level of middle ear disease. J Ass Res Otolaryngol. 2003;4:123-9.

32. Hugdahl K, LAW I, Kyllingsbaek S, Bronnick K, Gade A, Paulson OB. Effects of attention on dichotic listening: an O-PET study. Hum Brain Mapp. 2000;10:87-97.

33. Hungria $\mathrm{H}$. Otite média serosa/secretora. In: Hungria $\mathrm{H}$. Otorrinolaringologia. Rio de Janeiro: Guanabara Koogan; 2000. p.392-8.

34. Jäncke L, Specht K, Shah JN, Hugdahl K. Focused attention in a simple dichotic listening task: an fMRI experiment. Cog Brain Res. 2003;16:257-66.

35. Jäncke L, Steinmetz $H$, Volkmann J. Dichotic listening: what does it measure? Neuropychol. 1992;30(11):941-50.

36. Johnsen BH, Laberg JC, Eid J, Hugdahl K. Dichotic listening and sleep deprivation: vigilance effects. Scan J Psychol. 2002; 43:413-7.

37. Jung TTK, Alper CM, Roberts JE, Casselbrant ML, Eriksson PO, Gravel JS et al. Recent advances in otitis media: complications and sequelae. Ann Otol Rhinol Laryngol suppl. 2005;194:140-60.

38. Keith RW. ACPT: Auditory continuous performance test. San Antonio: Psychological Corporation; 1994.

39. Kimura D. Speech lateralization in young children as determined by an auditory test. J Comp Physiol Psychol. 1963;56:899-902.

40. Kimura D. Functional asymmetry of the brain in dichotic listening. Cortex. 1967;3:163-78.

41. Klausen O, Moller $P$, Holmefjord A, Reisaeter S. Lasting effects on otitis media with effusion on language skill and listening performance. Acta Otolaryngol. 2000;543:73-6.

42. Kupietz SS, Richardson E. Children's vigilance performance and inattentiveness in the classroom. J Child Psychol Psychiat. 1977;19:145-54.

43. Laures JS. Auditory vigilance of linguistic and nonlinguistic stimuli in individuals with aphasia. Brain Lang. 2003;87:154-55.

44. Lipschutz B, Kolinsky R, Damhaut P, Wikler D, Goldman S. Attentiondependent changes of activation and connectivity in dichotic listening. Neuro Image. 2002;17:643-56.

45. Lundy-Ekman L. Desenvolvimento do sistema nervoso. In: Lundy-Ekman L. Neurociência: fundamentos para a reabilitação. Rio de Janeiro: GuanabaraKoogan; 2000. p. 55-68. 
46. Mahone EM. Measurement of attention and related functions in the preschool child. Mental Retard Dev Disab. 2005;11:216-25.

47. Mcgee RA, Clark SE, Symons DK. Does the Conner's Continuous performance Test aid in ADHD diagnosis? J Abnorm Child Psychol. 2000;28(5):415-24.

48. Medwetsky L. Central auditory processing. In: Katz J, Burkard RF, Medwetsky L, editors. Handbook of clinical audiology. Baltimore: Williams \& Wilkins; 2002. p. 495-509.

49. Minard CGC, Feniman MR, Sousa ACF. Como estão as habilidades auditivas das crianças com fissura labiopalatina? In: Anais do IV Encontro Científico da Pós-Graduação do Hospital de Reabilitação de Anomalias Craniofaciais; 2001; Bauru, SP. p.36.

50. Minter KR, Roberts JE, Hooper SR, Burchinal MR, Zeisel SA. Early childhood otitis media in relation to children's attention-related behavior in the first six years of life. Pediatrics. 2001 May;107(5):1037-42.

51. Mirsky AF, Pascualvaca DM, Duncan CC, French LM. A model of attention and its relation to ADHD. Mental Retard Dev Disab. 1999;5:169-76.

52. Morton BE, Rafto SE. Corpus callosum size is linked to dichotic deafness and hemisphericity, not sex or handedness. Brain Cog. 2006;62:1-8.

53. Moss ALH, Fonseca S. Audiological issues in children with cleft lip and palate in one area of the U.K. Cleft Palate Craniof J. 2006;43(4):420-8.

54. Mukari SZ, Keith RW, Tharpe AM, Johnson CL. Development and standardization of single and double dichotic digit tests in the Malay language. Int J Audiol. 2006;45:344-52.

55. Neter J, Kutner MH, Wasserman W, Nachtsheim CJ. Applied Linear Statistical Models. New York: Springer Verlag; 1996.

56. Ortiz KZ. Teste de escuta dicótica: atenção seletiva para sons verbais e não-verbais em universitários destros.[Dissertação]. São Paulo(SP):

Universidade Federal de São Paulo - Escola Paulista de Medicina; 1995.

57. Ortuño F, Ojeda N, Arbizu J, López P, Martí-Climent JM, Peñuelas I et al. Sustained attention in a counting task: normal performance and functional neuroanatomy. Neuro Image. 2002;17:411-20.

58. Pereira LD. Sistema auditivo e desenvolvimento das habilidades auditivas. In: Ferreira LP, Befi-Lopes DM, Limongi SCO, editors. Tratado de fonoaudiologia. São Paulo: Rocca; 2004. p. 547-52.

59. Pope AW, Snyder HT. Psychosocial adjustment in children and adolescents with a craniofacial anomaly: age and sex patterns. Cleft Palate Craniof J. 2005;42(4):349-54.

60. Riccio CA, Cohen MJ, Hynd GW, Keith RW. Validity of the auditory continuous performance test in differentiating central processing auditory disorders with and without ADHD. J Learn Disabil. 1996;29(5):561-6. 
61. Roberts J, Hunter L, Gravel J, Rosenfeld R, Berman S, Haggard M et al. Otitis media, hearing loss, and language learning: controversies and current research. Dev Behav Pediat. 2004;25(2):110-22.

62. Roberts JE, Burchinal MR, Clarke-Klein SM. Otitis media in early childhood and cognitive, academic, and behavior outcomes at 12 years of age. $\mathrm{J}$ Pediatr Psychol. 1995;20(5):645-60.

63. Roberts JE, Burchinal MR, Zeisel SA, Neebe EC, Hooper SR, Roush J et al. Otitis media, the caregiving environment, and language and cognitive outcomes at 2 years. Pediatrics. 1998;102(2):346-54.

64. Roberts JE, Burchinal MR, Zeisel SA. Otitis media in early childhood in relation to children's school-age language and academic skills. Pediatrics. 2002;110(4):696-706.

65. Saes SO, Goldberg TBL, Mantovani JC. Secreção de orelha média em lactentes: ocorrência, recorrência e aspectos relacionados. J Pediatr. 2005;81(2):133-8.

66. Santos MFC. Processamento auditivo central: teste dicótico de dígitos em crianças e adultos normais. [Tese]. São Paulo (SP): Universidade Federal de São Paulo - Escola Paulista de Medicina; 1998.

67. Santos MFC, Pereira LD. Escuta com dígitos. In: Pereira LD, Schochat E. Processamento auditivo central: manual de avaliação. São Paulo: Lovise; 1997. p. 147-50.

68. Santos MFC, Ziliotto KN, Monteiro VG, Hirata CHW, Pereira LD, Weckx LLC. Avaliação do processamento auditivo central em crianças com e sem antecedentes de otite média. Rev Bras Otorrinolaringol. 2001;67(4):448-54.

69. Schwid SR, Tyler CM, Scheid EA, Weinstein A. Cognitive fatigue during a test requiring sustained attention: a pilot study. Mult Scler. 2003;9:503-8.

70. Shinn JB, Baran JA, Moncrieff DW, Musiek FE. Differential attention effects on dichotic listening. J Am Acad Audiol. 2005;16:205-18.

71. Souza LB, Souza VMC. Avaliação comportamental das habilidades auditivas centrais. In: Aquino AMCM, org. Processamento auditivo: eletrofisiologia e psicoacústica. São Paulo: Lovise; 2002. p. 129-34.

72. Spina V, Psillarkis JM, Lapa FS, Ferreira MC. Classification of cleft lip and cleft palate: suggested changes. Rev Hosp Clin Fac Med São Paulo. 1972;27(1):5-6.

73. Stewart MG, Ohlms LA, Friedman EM, Sulek M, Duncan NO, Fernandez AD et al. Is parental perception an accurate predictor of childhood hearing loss?: a prospective study. Otolaryngol Head Neck Surg. 1999;120:340-4.

74. Stollman MHP, Neijienhuis KAM, Jansen S, Simkens HMF, Snik AFM, Broek P. Development of an auditory test battery for young children: a pilot study. Int J Audiol. 2004;43:330-8. 
75. Teele DW, Klein JO, Chase C, Menyuk P, Rosner BA, Allen C et al. Otitis media in infancy and intellectual ability, school achievement, speech, and language at age 7 years. J Infect Dis. 1990;162:685-94.

76. Thompson RF. Ciclo vital do cérebro: desenvolvimento, plasticidade e envelhecimento. In: Thompson RF. O cérebro: uma introdução à neurociência. São Paulo: Santos Editora; 2005. p.319-54.

77. Tunçbilek G, Ozgur F, Belgin E. Audiologic and tympanometric findings in children with cleft lip and palate. Cleft Palate Craniofac J. 2003 May;40(3):304-9.

78. Welsh TN, Elliott D. Gender differences in a dichotic listening and movement task: lateralization or strategy? Neuropsychol. 2001;39:25-35. 
Alrotraxt 



\section{ABSTRACT}

\section{Auditory attention ability in $\mathbf{7}$ years old cleft palate and lip children: comparative study}

Cleft lip and palate indicates risk to alterations in the middle ear. These risks may impair the development of some hearing abilities, such as attention, which is essential to learn new abilities, including oral and written communication. Studies on attention process with the population with cleft lip and palate are recent and not widely found in literature. Therefore, this study can contribute to the area. The aims of this study were to examine children with this craniofacial anomaly through two tests: The SAAAT and the Dichotic Digit test - directed hearing stage which evaluated the hearing attention processes; to compare the results with a group without cleft lip and palate; to verify the association between the two tests. 55 children, both genders, aged 7 to 7 years and 11 months old were divided in two groups to be submitted to the study. Experimental group consisted of children with cleft lip and palate and Control group consisted of children without it. Both groups were assessed through a questionnaire, conventional hearing tests battery, the Sustained Auditory Attention Ability test (SAAAT) (Feniman, 2004), and the Dichotic Digit test directed hearing stage (Santos; Pereira, 1997). Experimental group showed lower performance than the control group in all kinds of answers of the SAAAT and, significant difference regarding decrease in vigilance $(p=0,014)$. In the Dichotic Digit test the experimental group showed lower percentages of right answers than the control group, not only for the right ear but also for the left ear. 
Statistic analysis showed significant interaction between group and gender $(p=0,026)$. When compared, the SAAAT and the Dichotic digit test had low association $\left(R^{2}=0,27\right)$. Experimental Group presented lower performance in the SAAAT only at the vigilance decrease. At the Dichotic Digit test female children with cleft lip and palate presented lower scores of right answers than the Control group. The SAAAT and The Dichotic Digit test - directed hearing stage - were not closely associated. Thus, it is possible to assume that different abilities are responsible for the performance in both tests.

Keywords: Cleft Palate. Attention. Sensory Deprivation. Otitis Media with Effusion. 